\title{
Wide Area Information-Based Transmission System Centralized Out-of-Step Protection Scheme
}

\author{
Igor Ivanković ${ }^{1}$, Igor Kuzle ${ }^{2, *}$ and Ninoslav Holjevac ${ }^{2}$ \\ 1 Croatian Transmission System Operator Ltd., 10000 Zagreb, Croatia; igor.ivankovic@hops.hr \\ 2 Department of Energy and Power Systems, Faculty of Electrical Engineering and Computing, \\ University of Zagreb, 10000 Zagreb, Croatia; ninoslav.holjevac@fer.hr \\ * Correspondence: igor.kuzle@fer.hr; Tel.: +385-1-6129-875
}

Academic Editor: Rodolfo Araneo

Received: 15 February 2017; Accepted: 28 April 2017; Published: 5 May 2017

\begin{abstract}
A wide area monitoring system (WAMS) with reliable telecommunication infrastructure can be expanded and enhanced with additional protection and control functionalities using synchronized phasor data measurements. With that aim, we have developed a multifunctional line protection (MFLP) model with both system and back-up protection functions. Theoretical premises based on transmission and relay protection system knowledge, together with the experience gathered from the operation of existing wide area systems, were used to develop the proposed model. Four main groups of simulation scenarios were defined in order to test the newly implemented functions. The results of the simulation process confirm the assumptions underlying the design of our MFLP module. Simulation results are then used for definition of the protection criteria required for implementation of the wide area protection algorithm in a control center. Conclusions drawn from the protection responses of the proposed algorithm that strengthen the algorithm design process are elaborated in the paper. The main contribution of the paper is the design and development of a centralized MFLP algorithm based on synchronized phasor data that is able to issue a trip command to a circuit breaker before an out-of-step condition occurs.
\end{abstract}

Keywords: wide area monitoring protection and control; synchrophasor data; multifunctional line protection (MFLP); out-of-step protection

\section{Introduction}

Protection and control systems in modern transmission networks are divided into three basic layers, as depicted on Figure 1. The first layer consists of independent transmission lines, transformer and busbar relay protection systems with a bay computer (BC) and a station computer (SC) responsible for execution. Systems and intelligent electronic devices (IED) in this layer run automatically in time domains ranging from milliseconds to minutes with the local data stream from an instrument transformer. In the third layer there are systems and applications for controlling the entire transmission power system, utilizing all available power system data. Actions in the control room are executed in automatic and manual mode.

Powers system estimation [1], system disturbance monitoring [2], observability and detection [3] are important features of smart transmission system network automation and protection system. This system includes wide area control and wide area protection, which constitute the wide area monitoring, protection and control (WAMPAC) system [4,5]. There has been a massive deployment of phasor measurement units (PMU) across transmission networks [6-8]. Therefore, information synthesis can be performed at a control center to control and protect transmission network during various disturbances and even predict potential power swings [9]. 
The second layer includes a central WAMPAC system, usually located in national/transmission area control centers (NCCs). The main data source (DS) for this protection system is phasor data measurements from PMUs. Execution times for this system are in the range from a few hundred milliseconds to minutes. WAMPAC applications use synchronized data to protect the wider transmission network, like an extension of the local line relay protection functions and some advanced system protection functions (e.g., out-of-step [10,11]). Occurrence of out-of-step conditions can have serious consequences $[12,13]$. This second layer is interconnected with both the first and the third layers.

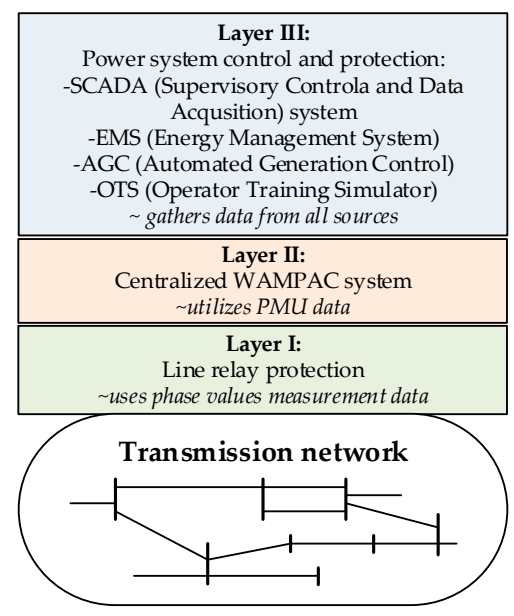

Figure 1. Hierarchical structure of layers for control and protection of power system.

A WAMPAC system should be fully incorporated and connected to the central SCADA (Supervisory Control and Data Acquisition) system to extend the control and protection functionality for the transmission network (Figure 2). Usually, a SCADA system consists of several DS, remote terminal units (RTU), SCs, electronic highways (DSs from other transmission system operators (TSOs)) and back-up (redundant) measurement systems for interconnection lines. WAMPAC systems are being developed to cover the deficiencies of the currently used protection systems in different countries (e.g., the Latvian system [14]). This paper uses the Croatian transmission system as a study case.

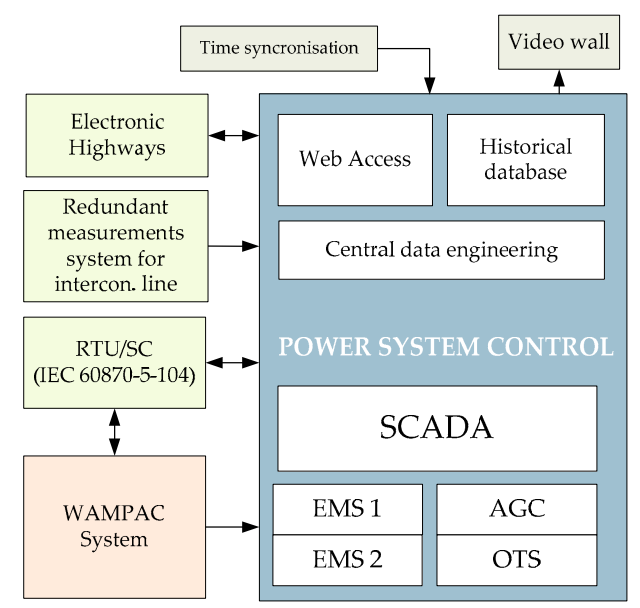

Figure 2. Structure of central power system control system with new wide area monitoring, protection and control (WAMPAC) system applications. RTU: remote terminal units; SC: station computer. 
A prerequisite for a WAMPAC system is to have an efficient communication infrastructure available to the TSO. Availability of optical fibers following the high voltage transmission line pathway enhanced with the communication IED enables the development of a WAMPAC system. This communication infrastructure has been installed throughout the last decade and it presents no additional capital cost burden for WAMPAC project development. What needs to be assured is the satisfactory reliability and time delay that are very strict for protection purposes since final command signals need to be issues in time frame shorter than $200 \mathrm{~ms}$. Each communication pathway for a dedicated PMU device has two routes. Main and reserve paths utilize different physical infrastructures. Table 1 presents delays through the communications infrastructure.

Table 1. Time delays in communication infrastructure for main and reserve information pathways.

\begin{tabular}{ccccc}
\hline $\begin{array}{c}\text { 400 kV Transformer } \\
\text { Substation }\end{array}$ & $\begin{array}{c}\text { Main Pathway } \\
\text { Length } \mathbf{( k m )}\end{array}$ & $\begin{array}{c}\text { Main Pathway } \\
\text { Delay (ms) }\end{array}$ & $\begin{array}{c}\text { Reserve Pathway } \\
\text { Length (km) }\end{array}$ & $\begin{array}{c}\text { Reserve Pathway } \\
\text { Delay (ms) }\end{array}$ \\
\hline Ernestinovo & 270 & 1.80295 & 320 & 2.20360 \\
Zerjavinec & 35 & 0.60058 & 190 & 1.20260 \\
Tumbri & 15 & 0.60048 & 40 & 0.80080 \\
Melina & 150 & 0.80135 & 320 & 1.40235 \\
Konjsko & 360 & 0.80340 & 410 & 1.80365 \\
Velebit & 270 & 1.72059 & 450 & 2.78630 \\
\hline
\end{tabular}

${ }^{1}$ All values presented have been validated with the TSO at the National control center.

The WAMPAC system must have a connection to the station and BC at substations in order to relay the circuit breaker trip commands and other issued alarm signals. Alarms and protection events are parts of the SCADA alarm and event list and therefore a communications link toward the SCADA system has to be available for the required data transfer. Data from phasor data concentrators (PDCs) can also be used in advanced and hybrid energy managements system (EMSs). Additional functions in central control centers for automatic generation control (AGC) and operator training simulators (OTSs) can be improved with the integration of the WAMPAC system data stream.

The basic system architecture for WAMPAC applications relies on the existing WAM system $[15,16]$ which is expanded with additional functionalities. The central system protection (CSP) system that is the most important part of a WAMPAC system has two main components: the multifunctional line protection (MFLP) part and the central protection function (CPF) part. At the end of the design process the CPF system is created. CPF relies on values generated in MFLP and compares these values for a whole transmission network to perform the needed operations. A suggested power system control and protection system structure is depicted in Figure 3.

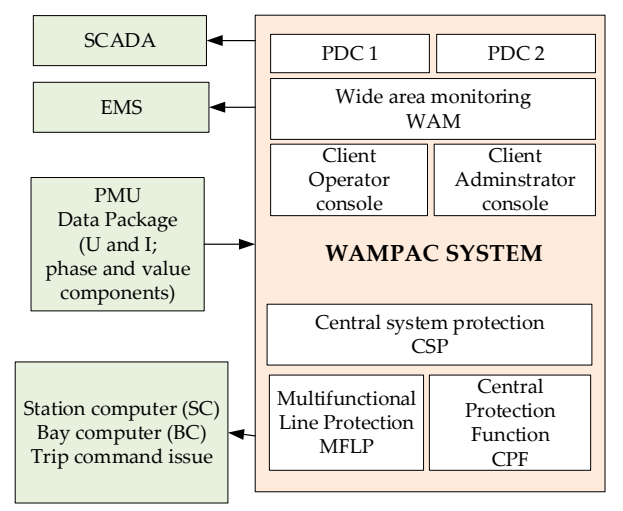

Figure 3. WAMPAC system structure with connections to the central power system control.

It is necessary to obtain an early warning and alarming for a fast identification of network disturbances of any kind. To improve the traditional solutions for transmission network protection, 
it is necessary to search for new strategies in that particular protection technical area. Phasor data- based network protection can comprehensively cover system disturbances in transmission networks. CSP is designed as a part of WAMPAC system.

The presented WAMPAC system was modeled in the Matlab [17] simulation environment and it is based on a phasor data stream concentrated in the main control center. The presented concept for multifunctional lines protection (MFLP) is also based on phasor data measurements and was also modeled and designed in the Matlab simulation environment. The most common transmission system operations behavior and characteristic disturbances were simulated to verify the model and acquire new data to enhance and improve the presently installed protection system.

The phasor data stream was obtained from the simulation environment through the measurement module in a Matlab model that emulates a real PMU device. Positive sequence values of voltage and current were used for measurement and protection purposes of all $400 \mathrm{~kW}$ transmission lines. The work presented here is a substantial extension of research presented in a conference paper by the same authors $[18,19]$.

\section{Multifunctional Line Protection}

In continental Europe, the $400 \mathrm{kV}$ transmission network is the power system backbone. Full observations of all segments in all operational conditions is the main task of the TSOs. There is an ongoing massive deployment of PMUs across the system. The Croatian TSO has already installed PMU devices at all $400 \mathrm{kV}$ transmission lines and the work presented in this paper focuses on development of the advanced protection functionalities that require wide PMU coverage. The prerequisite for such wide coverage of transmission system with PMU measurements is a strong requirement that is not easily fulfilled, but the presented case-study from a real system demonstrates the capabilities and potential that algorithm based on such data coverage can have. The current trends and efforts in the development of transmission systems head toward massive deployment of PMU devices and MFPL algorithm presented in this paper even with its limitations could provide insights and benefit for further development.

Transmission line back-up protection design is a sensitive process that depends on many factors. Current TSO protection strategies rely entirely on using differential protection strategies which have clear and sharp boundaries with good protection selectivity criteria but are sensitive to topology and impedance changes. Utilization of PMU data can help develop functions not dependent on impedance values and protection device setting and enable the design of protection functions using phase angle values. In the future back up protection solutions for transmission networks not entirely covered with PMU devices (e.g., segments of $220 \mathrm{kV}$ transmission networks) that would have to rely on state estimation are expected to be researched. Recent research work $[20,21]$ highlights the importance of WAMPAC systems in transmission networks. A list of basic features of different technical solutions for advanced protection systems is presented in Table 2. It is important to note that for a transmission system of a larger scale compared to the study-case example the size of the system presents an obstacle that has not been solved. The solution must be headed in the direction of effective division of a large system into smaller control zones that would run advanced protection algorithms in parallel.

The most common technique for out-of-step protection uses impedance measurements implemented into relay protection devices. The resistance-based ( $\mathrm{R}$ dot) technique is rarely used. Voltage-based and swing voltage center-based methods are also not commonly used due to their sensitivity in the setting phase stemming from source impedance values and power system reduction to the required two-machine model. Tracing generator angles in some transmission control centers is not so common. All of these methods only have local measurement data available. A WAMPAC system has measurements from a wider transmission network and does not depend on network element configurations. Others methods, like fuzzy logic-based and neural network-based, are still in the development phase and for now cannot be used in real applications in transmission network control centers. 
WAMPAC systems are critically dependent on the communication equipment and potential delays. Preliminary evaluation focused on execution time for such algorithms shows that communications infrastructure time has an acceptable time delay in range of $50 \mathrm{~ms}$ and the delay time on server machines in control centers $(<10 \mathrm{~ms})$ is not a limitation for protection reactions. This means that the transfer of developed applications in a simulations environment to the real technical world is possible and will be the focus of future work.

Table 2. Basic features of out-of-step protection methods.

\begin{tabular}{|c|c|c|c|c|c|}
\hline Method & $\begin{array}{c}\text { Line End } \\
\text { Measure-Ment }\end{array}$ & $\begin{array}{l}\text { Wide Area } \\
\text { Measure-Ment }\end{array}$ & $\begin{array}{l}\text { Independent from } \\
\text { Setting }{ }^{1} \text { Process }\end{array}$ & $\begin{array}{l}\text { Real Time } \\
\text { Application }\end{array}$ & Demerits \\
\hline $\begin{array}{c}\text { Fuzzy } \\
\text { logic/clustering } \\
\text { based (e.g., [9]) }\end{array}$ & $\checkmark$ & $\times$ & $\times$ & $\times$ & study work phase \\
\hline $\begin{array}{l}\text { WAMPAC system } \\
(\text { e.g., [10]) }\end{array}$ & $\checkmark$ & $\checkmark$ & $\checkmark$ & $\checkmark$ & Communication requirements \\
\hline $\begin{array}{l}\text { Energy function } \\
\text { based(e.g., [11]) }\end{array}$ & $\checkmark$ & $\times$ & $x$ & $\times$ & study work phase \\
\hline $\begin{array}{l}\text { Generator angle } \\
\text { based (e.g., [13]) }\end{array}$ & $\checkmark$ & $\times$ & $\checkmark$ & $\checkmark$ & $\begin{array}{c}\text { availability of generator } \\
\text { measurements, communication } \\
\text { requirements }\end{array}$ \\
\hline $\begin{array}{l}\text { Equal area based } \\
\quad(\text { e.g., [20]) }\end{array}$ & $\checkmark$ & $\times$ & $x$ & $\times$ & $\begin{array}{l}\text { Inertia values }(\mathrm{H}) \text { for generators and } \\
\text { parts of the system needed, system } \\
\text { reduction, study work phase }\end{array}$ \\
\hline $\begin{array}{l}\text { Apparent impedance } \\
\text { trajectory based } \\
\text { (e.g., [22]) }\end{array}$ & $\checkmark$ & $\times$ & $\checkmark$ & $\checkmark$ & Communication requirements \\
\hline $\begin{array}{l}\text { Resistance based } \\
\text { (e.g., [23]) }\end{array}$ & $\checkmark$ & $\times$ & $x$ & $\checkmark$ & study work phase \\
\hline $\begin{array}{c}\text { Voltage based } \\
\text { (e.g., [24]) }\end{array}$ & $\checkmark$ & $\times$ & $x$ & $\checkmark$ & $\begin{array}{l}\text { source impedances dependent, } \\
\text { study work phase }\end{array}$ \\
\hline $\begin{array}{c}\text { Swing } \\
\text { voltage/Speed } \\
\text { acceleration criterion } \\
\text { based (e.g., [25]) }\end{array}$ & $\checkmark$ & $\times$ & $x$ & $\checkmark$ & $\begin{array}{l}\text { voltage on source dependent, study } \\
\text { work phase, system reduction } \\
\text { (2 machines) approximation }\end{array}$ \\
\hline $\begin{array}{l}\text { Neural network } \\
\text { based (e.g., [26]) }\end{array}$ & $\checkmark$ & $\times$ & $x$ & $\times$ & study work phase \\
\hline $\begin{array}{l}\text { Impedance based } \\
\text { (e.g., [27]) }\end{array}$ & $\checkmark$ & $\times$ & $x$ & $\checkmark$ & $\begin{array}{l}\text { source impedances dependent, } \\
\text { study work phase }\end{array}$ \\
\hline
\end{tabular}

${ }^{1}$ Protection setting process is sensitive to network configurations.

One of the defining protection functionalities of the WAMPAC system is a MFLP. It has two main modules [27-30]: system protection function module and line back-up protection function module (Figures 4 and 5). Conditions at each transmission line ends are covered with PMU measurement data and data gathered from the SC and the $\mathrm{BC}$.

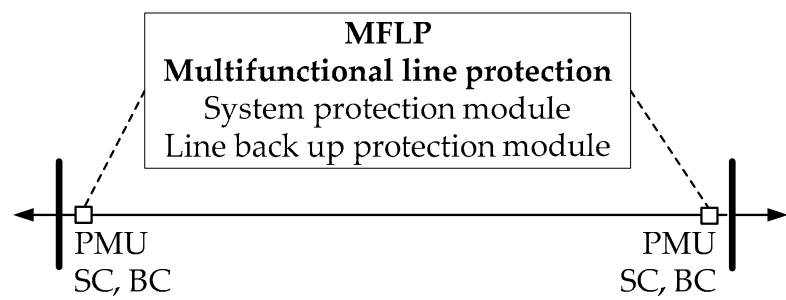

Figure 4. Multifunctional line protection (MFLP), MFLP concept with system and line back up protection that uses data from phasor measurement unit (PMU) devices at both line ends and station and/or bay computers (BCs) in substations. 


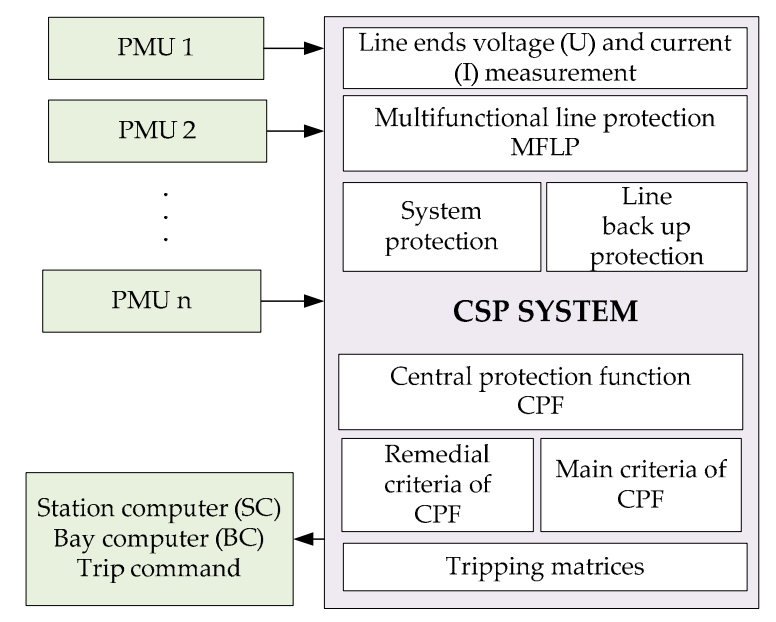

Figure 5. Detailed internal design of the central system protection (CSP) which is a part of a WAMPAC system.

To be able to respond to system wide transmission network disturbances (voltage, frequency and angle instability) in a proper way, the system protection function must be parametrized carefully in the setting phase. Phasor data streams from different parts of the transmission network must be collected in the control center. The collection of these data in real time enables realization of the backup line function module of the MFLP. Line back up protection functions are important both because of back up protection criteria and for system real time protection criteria. From the phasor data measurement additional alarming, monitoring, and protection criteria can be obtained in order to preserve transmission stability.

CSP (Figure 5) in this particular case was designed for angle stability issues in the transmission network [31-33]. This algorithm for central protection application deals with active power oscillations and out-of-step conditions in the transmission network.

Available phasor data technology has recently been used on the basis of gathered knowledge and experience from the operation of classical numerical line protection. Line protection devices have well-proven and efficient protection functions. These protection functions have two different functionalities which are incorporated in a single piece of hardware or IED. The first and main functionality is to protect a line from a fault (e.g., short circuit) and the second one is system functionalities which provide various system functions.

Usage of different system functions [5] in these protection devices has some obstacles. In general, it is hard to achieve full system observability just from one point in the system. Regular line protection has available data measured only from one transmission line end. Rarely is the measurement data from other line end available. Line differential protection exchanges the data between both ends but only for a limited data range. That is the reason why during system disturbance it is difficult to realize advanced system protection functions since all the required data streams are not available.

\subsection{MFLP Functions in WAMPAC System}

The basis for both groups of protection functions (system and line back-up protection) are positive sequence components of measurements from PMU devices. The PMU data represents a sufficient foundation to handle symmetrical three phase system disturbances and line faults. MFLP is tuned and oriented to track conditions in four operating stages of the transmission network for angle stability enhancement:

(1) Normal operating condition in the transmission network tracing the execution of the day-ahead plans cycle ( $24 \mathrm{~h}$ ahead). Network operation footprint will be traced and all line breaker switching 
operations will be recognized in accordance with the plan [34,35]. All critical system values are monitored.

(2) Short circuit conditions in the wider transmission network are monitored and recognized in line back up protection functions. Selectivity criteria help locate the exact position of short circuit faults. Circuit breaker tripping criteria are generated based on the gathered data.

(3) Power swing conditions in transmission network with the available measurements can be recognized with the availability of the right data. In those circumstances an alarm is generated and if needed circuit breaker switching/tripping must be carried out to prevent more serious consequences.

(4) If the system is about to reach out-of-step conditions these are also recognized in time and the transmission network is again separated in order to prevent more serious consequences.

Table 3 lists realized system protection and line backup protection functions in developed Matlab model with the purpose of monitoring transmission network operations and prevent angle instability. All functions are realized assuming the availability of phasor data measurements.

Table 3. MFLP algorithm segments realized in the developed Matlab model.

\begin{tabular}{ccc}
\hline \multirow{2}{*}{ No. } & \multicolumn{2}{c}{ Protection and Monitoring Functions } \\
\cline { 2 - 3 } & System Protection & Line Back up Protection \\
\hline 1. & Phase angle difference $(\Delta \varphi)$ & Over current protection \\
2. & Rate of change of angle (angle velocity) $\omega$ & Over load protection \\
3. & Angle acceleration $\alpha$ & Line differential protection $(\Delta I)$ \\
4. & Rate of change of voltage & Line impedance protection \\
5. & Rate of change of current & Under voltage protection \\
6. & Rate of change of active power & Over voltage protection \\
7. & Rate of change of reactive power & Voltage monitoring \\
8. & Rate of change of resistance & Current monitoring \\
9. & Rate of change of reactance & Active power monitoring \\
10. & Rate of change of impedance & Reactive power monitoring \\
11. & Equivalent inertia constant of the system & Impedance monitoring \\
\hline
\end{tabular}

Tracking of all values listed in the table above (Table 3) is a prerequisite for the definition of additional criteria for advanced protection functions. Key performance indices are calculated and defined for these values in order to be used as an input for protection settings.

System protection functions are the focus of the development process. The goals were to design an application in a simulation environment capable of reacting to system disturbances like angle stability. These functionalities are associated and linked to a particular transmission line. Knowledge and experience from the operation of the currently installed WAM systems underlines a need to also track other electrical values besides voltages and currents, so the rate of change of voltage, rate of change of current, rate of change of power and rate of change of impedance are added. These values are utilized in the protection system design process.

\subsection{Protection Criteria}

A major task of new general criteria in MFLP is the angle observation throughout the transmission network to prevent angle instability [36-39]. The new algorithm utilizes collected and available angle measurements of existing WAM systems. Besides angle values, values of angle velocity and angular acceleration that are crucial to detecting angle instabilities are continuously calculated and monitored.

Usually, protection schemes distinguish between short circuits and other disturbances like power swing oscillations by means of the impedance trajectory [40]. Relay protection knowledge and experience push the development of algorithm in the direction of achieving independence from using 
values which depend on transmission system impedance. The developed algorithm described in this paper uses impedance independent values (power and angle values).

The outcomes of angle instabilities are out-of-order values of power flows, currents and voltages. Monitoring of these values and their rate of change is therefore important. Various threshold criteria are obtained from these measurements.

\subsection{System Protection Algotithm}

System protection functions are based on processing angle values $(\varphi)$ of busbar voltage. General criteria for voltage angle difference across transmission network can be expressed as in Equation (1) and applied for both dense and meshed transmission systems. The aim is to observe the angle difference across all transmission lines ( $N$ represents the busbar number). For the case of the modelled transmission study case (the Croatian transmission system) the number of busses is 6 :

$$
\Delta \varphi_{i j}=\left(\varphi_{i}-\varphi_{j}\right), \quad i \in\{1 . . N\}, \quad j \in\{1 . . N\}, \quad i \neq j
$$

Out-of-step can spread through transmission network and can come to a pass on a particular line. Identification of this line is important. The angle differences on all lines has to be monitored since the largest angle difference occurs on transmission lines with out-of-step conditions compared to adjacent lines, as shown in Equation (2). These maximum values are used as the main criteria for generating tripping commands to circuit breakers:

$$
\Delta \varphi_{\mathrm{MAX}}=\max \left\{\left|\Delta \varphi_{12}\right|,\left|\Delta \varphi_{23}\right|, \ldots . .\left|\Delta \varphi_{i, j=i+1}\right|\right\} \quad i \in\{1 . . N\}, \quad j \in\{1 . . N\}, \quad i \neq j
$$

Angle differences on adjacent lines will be used as additional criteria for better disturbance positioning, as in Equations (3) and (4). Both sides of affected transmission lines have to be monitored $(-\Delta \varphi$ and $+\Delta \varphi)$. The values are also used to locate the zero voltage points on transmission lines (an indicator where in transmission network separation should be made):

$$
\begin{aligned}
& -\Delta \varphi_{i j}=\left(\varphi_{i-1}-\varphi_{j-1}\right) \quad i \in\{1 . . N\}, j \in\{1 . . N\}, i \neq j, \\
& +\Delta \varphi_{i j}=\left(\varphi_{i+1}-\varphi_{i+1}\right) i \in\{1 . . N\}, j \in\{1 . . N\}, i \neq j,
\end{aligned}
$$

Criteria for detection of an affected transmission lines with out-of-step condition $\left(\Delta \varphi_{O O S}\right)$, is expressed by Equations (5)-(7). Fulfilling all three of the criteria at the same time is a trigger to issue tripping commands to line circuit breakers:

$$
\begin{gathered}
\Delta \varphi_{\mathrm{OOS}}=\Delta \varphi_{i j}=\Delta \varphi_{\mathrm{MAX}} \\
\Delta \varphi_{\mathrm{OOS}}>\left|-\Delta \varphi_{i j}\right| \\
\Delta \varphi_{\mathrm{OOS}}>\left|+\Delta \varphi_{i j}\right|
\end{gathered}
$$

Impedances and power quantity values depend on system source impedances and other system parameters. The first and second derivative of the voltage angle difference (angle velocity and angle acceleration) are added as criteria for locating the transmission line affected by out-of-step condition. A selectivity criterion is vital to be obtained from the protection perspective and to achieve those additional criteria must be included into the remedial scheme (angle velocity and angle acceleration above the set limit as in Equations (8) and (9)):

$$
\frac{d \varphi}{d t}_{\text {LIMIT }}<\left\{\left|\frac{\mathrm{d} \varphi_{i j}}{\mathrm{~d} t}\right|\right\}, \quad i \in\{1 . . N\}, \quad j=i+1
$$




$$
\frac{d^{2} \varphi}{d t^{2} \text { LIMIT }}<\left\{\left|\frac{\mathrm{d}^{2} \varphi_{i j}}{\mathrm{~d} t^{2}}\right|\right\}, \quad i \in\{1 . . N\}, \quad j=i+1
$$

To obtain the characteristic footprint for these values in transmission network it is necessary to do simulations that will be explained in the following section of the paper. Out-of-step disturbance is characterized by strong voltage deviations. On transmission lines affected by this disturbance the voltage dip can almost reach zero volts on one transmission line end. During out-of-step conditions voltage lower limit almost reaches zero $\left(U_{\text {LOWER LIMIT }} \approx 0\right)$. This fact is used as an additional criterion (Equation (10)):

$$
U_{\text {LOWER LIMIT }}>\left\{U_{i}\right\}, \quad i \in\{1 . . N\}
$$

In order to assure a distinction between the short circuit fault and out-of-step conditions extra criteria were utilized. Three phase short circuits have certain features similar to out-of-step conditions. The most selective and well proven concept of line differential protection based on phasor data is used (Equation (11) shows the current difference). This criterion is also used for line back up protection. It is a very valuable criterion with a strictly defined and sharp operation edge.

$$
\Delta I_{i j}=\left|\overline{I_{i}}+\overline{I_{j}}\right|, \quad i \in\{1 . . N\}, \quad j=i+1
$$

\subsection{Line Back-Up Protection Algorithm}

Back-up functionalities for transmission lines are part of the WAMPAC system. These functionalities can be emulated with dedicated line relay protection functions inside MFLP. It is crucial to have line back up protection in order to achieve the same level of protection as in traditional relay protection devices. Protection functions in the MFLP model, like relay devices, use available line end voltage and current measurements, collected from PMUs and instrument transformers. Line end voltage $U_{\mathrm{L}}$ and current $I_{\mathrm{L}}$ are expressed as in Equations (12) and (13):

$$
\begin{aligned}
U_{\mathrm{L}}(t) & =U_{\mathrm{L}} \cdot\left[\cos \left(\omega \cdot t+\varphi_{U}\right)+j \cdot \sin \left(\omega \cdot t+\varphi_{U}\right)\right] \\
I_{\mathrm{L}}(t) & =I_{\mathrm{L}} \cdot\left[\cos \left(\omega \cdot t+\varphi_{I}\right)+j \cdot \sin \left(\omega \cdot t+\varphi_{I}\right)\right]
\end{aligned}
$$

Monitoring and protection functions were used for internal calculation of the complex expressions for line end voltage (Equation (14)) and line current (Equation (15)) measurements. These values are needed for other series of calculations:

$$
\begin{gathered}
\bar{U}_{\mathrm{L}}=\operatorname{Re}\left\{\bar{U}_{\mathrm{L}}\right\}+j \cdot \operatorname{Im}\left\{\bar{U}_{\mathrm{L}}\right\} \\
\bar{I}_{\mathrm{L}}=\operatorname{Re}\left\{\bar{I}_{\mathrm{L}}\right\}+j \cdot \operatorname{Im}\left\{\bar{I}_{\mathrm{L}}\right\}
\end{gathered}
$$

At the line end protection relay or MFLP through PMU measures line voltage $U_{L}$, defined as in Equations (16) and (17):

$$
\begin{aligned}
\bar{U}_{\mathrm{L}} & =R_{\mathrm{L}} \cdot \bar{I}_{\mathrm{L}}+j X_{\mathrm{L}} \cdot \bar{I}_{\mathrm{L}} \\
\operatorname{Re}\left\{\bar{U}_{\mathrm{L}}\right\}+j \operatorname{Im}\left\{\bar{U}_{\mathrm{L}}\right\} & =\left(R_{\mathrm{L}}+j X_{\mathrm{L}}\right) \cdot\left(\operatorname{Re}\left\{\bar{I}_{\mathrm{L}}\right\}+j \operatorname{Im}\left\{\bar{I}_{\mathrm{L}}\right\}\right)
\end{aligned}
$$

In order to emulate the impedance protection the same principal of complex expressions was used. Impedance measurement calculations for line protection function are constantly being compared to the pre-set values. Calculated impedance uses complex values (Equations (18) and (19)) and is needed for system and back up protection functions:

$$
X_{\mathrm{L}}=\frac{\operatorname{Im}\left\{\bar{U}_{\mathrm{L}}\right\} \cdot \operatorname{Re}\left\{\bar{I}_{\mathrm{L}}\right\}-\operatorname{Re}\left\{\bar{U}_{\mathrm{L}}\right\} \cdot \operatorname{Im}\left\{\bar{I}_{\mathrm{L}}\right\}}{\operatorname{Re}\left\{\bar{I}_{\mathrm{L}}\right\}^{2}+\operatorname{Im}\left\{\bar{I}_{\mathrm{L}}\right\}^{2}}
$$




$$
R_{\mathrm{L}}=\frac{\operatorname{Re}\left\{\bar{U}_{\mathrm{L}}\right\} \cdot \operatorname{Re}\left\{\bar{I}_{\mathrm{L}}\right\}+\operatorname{Im}\left\{\bar{U}_{\mathrm{L}}\right\} \cdot \operatorname{Im}\left\{\bar{I}_{\mathrm{L}}\right\}}{\operatorname{Re}\left\{\bar{I}_{\mathrm{L}}\right\}^{2}+\operatorname{Im}\left\{\bar{I}_{\mathrm{L}}\right\}^{2}}
$$

For advanced operations in a transmission network, the most commonly used impedance characteristic for distance protection function of a relay device is a polygon shaped characteristic. Distance protection uses specifically tailored characteristics for line protection. For remote back up protection more than one distance zone is needed. Based on the principles of the abovementioned equations the algorithm for line back up protection is defined.

Power swing and out-of-step functions use different and much wider impedance characteristics than distance protection. They characteristically use envelopes of all impedance zones of the distance protection and it is the most outer placed characteristic in the $R / X$ plane.

\subsection{Disturbance Origin Direction in Transmission Network}

Locations of short circuit faults in the observed transmission network can be located using the WAMPAC system. The same way active power oscillations in the system can also be traced utilizing the results from WAMPCA, specifically a CSP system. Short circuit and other system disturbances have different footprints. Patterns of three values will be utilized for that purpose: (1) busbar voltage values; (2) angle dynamics values (rate of change of angle (ROCOA)); (3) angle velocity values on transmission line. Busbar with the lowest voltage value indicates the disturbance origins (DO) happened on that busbar or somewhere in the vicinity, as shown by Equation (20):

$$
U_{i}=\min \left\{\left|U_{1}\right|,\left|U_{2}\right|, \ldots \ldots\left|U_{i}\right|\right\}
$$

Change of angle dynamics and angle velocity on a particular transmission line is described by Equations (21) and (22):

$$
\begin{aligned}
& \Delta \varphi_{i j}=\max \left\{\left|\Delta \varphi_{12}\right|,\left|\Delta \varphi_{23}\right|, \ldots .\left|\Delta \varphi_{i, j=i+1}\right|\right\} \\
& \frac{\mathrm{d} \varphi_{i j}}{\mathrm{~d} t}=\max \left\{\left|\frac{\mathrm{d} \varphi_{12}}{\mathrm{~d} t}\right|,\left|\frac{\mathrm{d} \varphi_{23}}{\mathrm{~d} t}\right|, \ldots\left|\frac{\mathrm{d} \varphi_{i, j=i+1}}{\mathrm{~d} t}\right|\right\}
\end{aligned}
$$

Parameters described above $\left(U_{i}, \frac{\mathrm{d} \varphi_{i j}}{\mathrm{~d} t}\right.$ and $\left.\Delta \varphi_{i j}\right)$ are used for the creation of protection criteria. This multi-criterion algorithm is needed for composite and cascading transmission network disturbances which are, unlike short circuit faults, hard to detect and locate. Implementing these criteria efficiently locates the DO (Equation (23)) and in observed transmission network faulted busbar or transmission line can be pointed out. Additionally, with the usage of these criteria the direction of the DO can also be determined:

$$
D O=\left\{\begin{array}{c}
\min U_{i} \\
\max \frac{\mathrm{d} \varphi_{i, j}}{\mathrm{dt}} \\
\max \Delta \varphi_{i, j}
\end{array} \text { for } i \in\{1 . . N\}, \quad j=i+1\right.
$$

\subsection{Equivalent System Inertia Observed from Single Transmission Line}

TSOs have all the necessary data from the transmission system, but in some cases data from generation units that are owned by generation companies is not available. The functions in WAMPAC applications preferably depend only on data from PMU devices installed on transmission lines that are under the TSO's supervision. Based on the classical model of generators, if we neglect the damping constant which does not affect natural frequencies, swing equitation for a single generator unit during angle instability can be expressed with Equation (24). Mechanical power from turbine $P_{\mathrm{m}}$ and electrical 
generator output $P_{\mathrm{e}}$ can be unbalanced. $M$ represents the angular momentum expressed in p.u. (Equation (25)), $H$ represents a normalized inertia constant and $\omega_{s}$ the angular speed:

$$
\begin{gathered}
\left.P_{\mathrm{m}}-P_{\mathrm{e}}=M \cdot \frac{\mathrm{d}^{2} \delta}{\mathrm{d} t^{2}} \quad \text { (p.u. }\right) \\
\left.M=\frac{2 H}{\omega_{\mathrm{s}}}=\frac{H}{\pi f} \quad \text { (p.u. }\right)
\end{gathered}
$$

The resulting moment $M$ changes the speed from nominal values and results with angular acceleration $\alpha$ on the generator terminals. Accelerating power $P_{a}$ is shown by Equation (26):

$$
\Delta P=P_{a}=M \cdot \alpha
$$

Accordingly, that segment of generation unit motion can be equivalently described for the high voltage transmission level with PMU data. Equation (26) can be adopted for the calculation of the equivalent system inertia $H_{\text {eq }}$ observed on the transmission line (Equation (27)). Both values needed are measured, difference in active power $\left(\Delta P_{\text {line }}\right)$ and angle (angle acceleration $\alpha_{\text {line }}$ ) between sending end and receiving end of the line:

$$
H_{\text {eq }}=\frac{\Delta P_{\text {line }}}{\alpha_{\text {line }}} \cdot \pi f
$$

These values are available from the MFLP module for each transmission line equipped with PMU devices. Active power difference $\Delta P_{\text {line }}$ can be defined with Equation (28). Active power during normal operation can be defined as $\Delta P_{\text {const }}$ and during a disturbance event active power on line will be changed and that power is denoted as $\Delta P_{\text {disturb: }}$ :

$$
\Delta P_{\text {line }}=P_{\text {const }}-P_{\text {disturb }}
$$

It is assumed that active power on sending and receiving transmission line ends is defined as follows (Equation (29)). Thus, line losses can be neglected:

$$
P_{\text {sending }}=P_{\text {receiving }}
$$

Both line ends have measurements for active power. During normal operation the conditions are as shown by Equation (30). Moment manifested on transmission line which can push transmission network towards angle instability is accordingly zero in normal operating conditions:

$$
P=\text { constant }, \quad \Delta P \cong 0, \quad \alpha \cong 0
$$

Angle instability in the transmission network will change the active power flow and the MFLP function will track that change. The change can be quantified with calculating the equivalent system inertia observed from the particular line and that value can be used as a supporting and additional input into the central protection scheme.

\section{Transmission Network and System Protection Model}

In order to accomplish the steps required for moving from the currently operational WAM system installed in the control center towards a full capability WAMPAC system, a simulation environment was developed in Matlab.

A detailed model of Croatian $400 \mathrm{kV}$ network [8] with PMU devices installed on all lines (Figure 6) is required to initiate the modeling and implementation of the WAMPAC system. The Matlab model for transmission network from Figure 6 together with the network equivalents were modeled. The CSP system with the structure depicted in Figure 5 was developed in Matlab. At this stage only positive 
sequence values were used. The Matlab Simulink simulation environment is used and the model is shown in Figure 7.

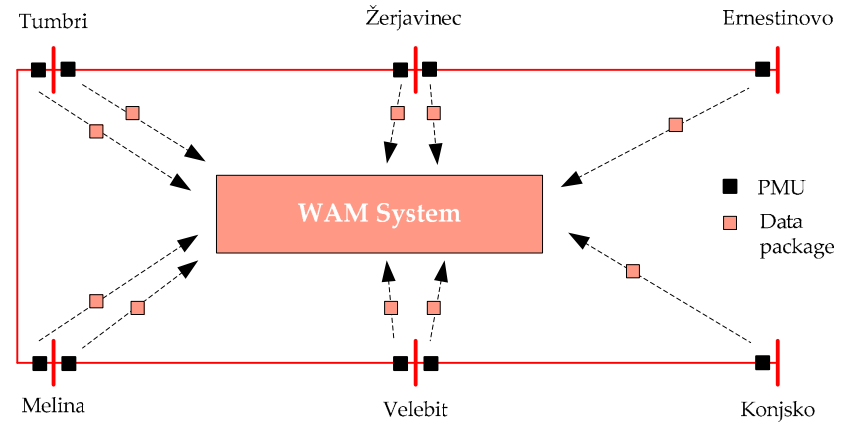

Figure 6. Block scheme of modeled Croatian $400 \mathrm{kV}$ transmission network with WAM system and PMU devices installed at each line end.

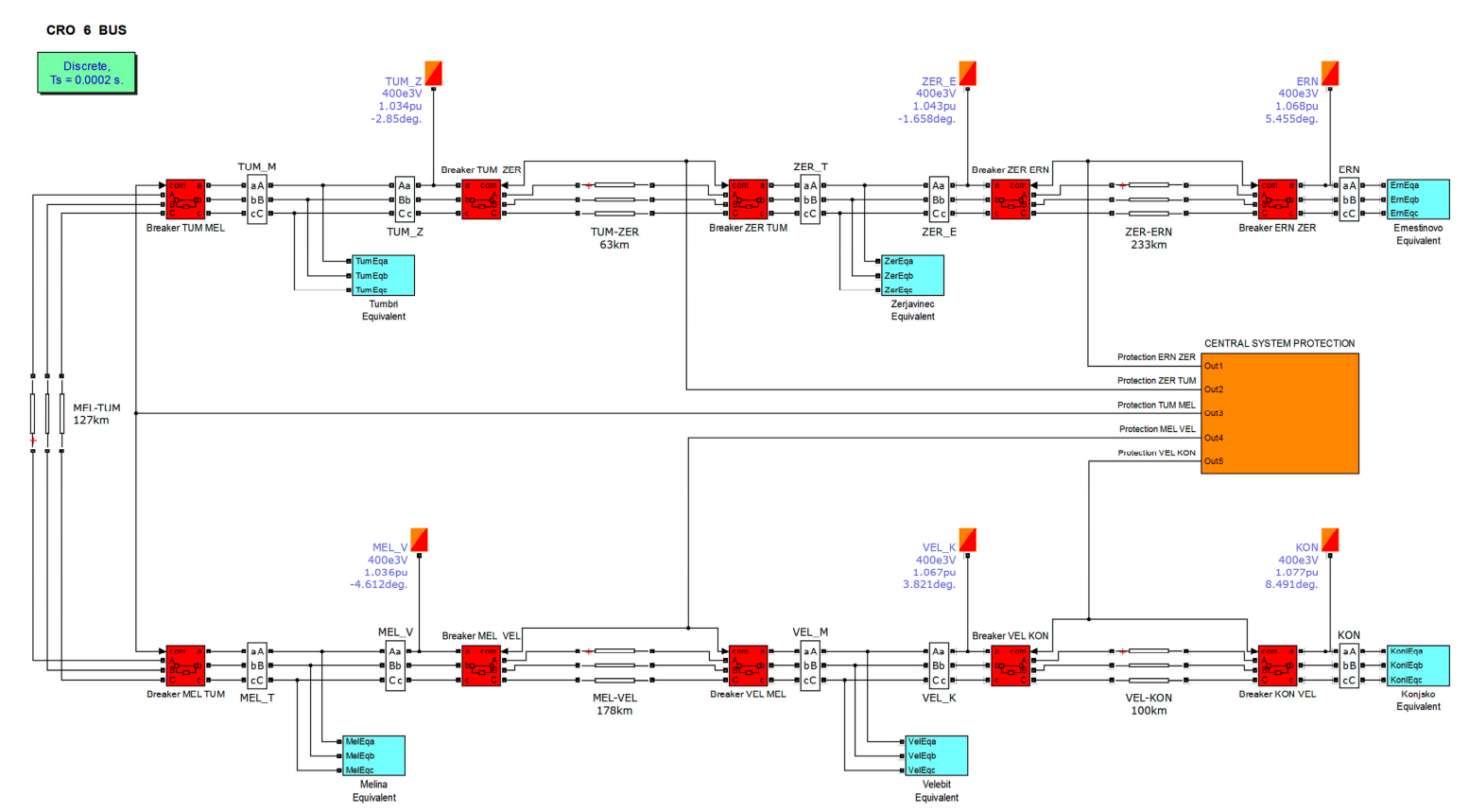

Figure 7. Modeled CSP in Matlab environment with $400 \mathrm{kV}$ transmission network model.

The data generated during the simulations is wholesome and well-structured and therefore the performed analyses have good value. The model needs to fulfill the following requirements:

- Inclusion of a three phase transmission network model;

- Implementation of power flow functionality with basic and intermediate characteristics;

- Adaptation of a simulations time domain of milliseconds;

- Simulation of line single phase short circuit faults;

- Capability for creation of different system disturbances;

- Design capability to create different protection functions.

The model was verified and validated with archived data for regular switching operations and with data gathered from various disturbances occurring in the transmission network [41-43]. The design and verification process of model are done in different phases. The first phase uses archived data for all transmission elements which are being modelled. In the second phase responses from the 
simulations are verified with transmission system events recorded data (various static scenarios like power flow and circuit breaker operations recorded by the WAM system, relay protection systems and SCADA system). The transmission AC line parameters shown in Table 4 are implemented in the model. One of the control methods in the design phase that can indicate wrong parameters measurements is fault propagation speed that is limited with its upper bound and depends on the capacitance and inductance of the lines.

Table 4. AC positive and zero line parameters for the modelled $400 \mathrm{kV}$ transmission network.

\begin{tabular}{cccccc}
\hline $\begin{array}{c}\text { AC Line } \\
\text { Parameters }\end{array}$ & ZER-ERN & TUM-ZER & MEL-TUM & MEL-VEL & VEL-KONJ \\
\hline $\mathrm{r} 1(\mathrm{Ohms} / \mathrm{km})$ & 0.0319 & 0.0308 & 0.0300 & 0.0340 & 0.0340 \\
$\mathrm{r} 0(\mathrm{Ohms} / \mathrm{km})$ & 0.1897 & 0.1222 & 0.1920 & 0.2500 & 0.2500 \\
$11(\mathrm{H} / \mathrm{km})$ & $1.0554 \times 10^{-3}$ & $1.021 \times 10^{-3}$ & $1.00964 \times 10^{-3}$ & $1.0859 \times 10^{-3}$ & $1.0859 \times 10^{-3}$ \\
$10(\mathrm{H} / \mathrm{km})$ & $2.3120 \times 10^{-3}$ & $2.136 \times 10^{-3}$ & $3.2800 \times 10^{-3}$ & $2.6560 \times 10^{-3}$ & $2.6560 \times 10^{-3}$ \\
$\mathrm{c} 1(\mathrm{~F} / \mathrm{km})$ & $11.0828 \times 10^{-9}$ & $11.493 \times 10^{-9}$ & $11.2102 \times 10^{-9}$ & $11.2102 \times 10^{-3}$ & $11.2102 \times 10^{-9}$ \\
$\mathrm{c} 0(\mathrm{~F} / \mathrm{km})$ & $4.9363 \times 10^{-9}$ & $6.847 \times 10^{-9}$ & $5.4140 \times 10^{-9}$ & $8.0255 \times 10^{-9}$ & $8.0255 \times 10^{-9}$ \\
length $(\mathrm{km})$ & 233 & 63 & 127 & 178 & 100 \\
\hline
\end{tabular}

${ }^{1}$ Distributed parameters used in the Matlab model $(3$ phase, $50 \mathrm{~Hz})$.

In order to have a flexible model for studying the different protections scenarios and faults a three phase circuit breaker representation is modeled. That way each phase can be independently controlled with an internal timer or with external control (protection function blocks). The opening time for circuit breakers is less than $100 \mathrm{~ms}$. Circuit breaker operations can be traced with PMU measurements after the identification of their characteristic footprint. The opening sequence of circuit breakers creates a discontinuity in the power flow on measured transmission lines. Those discontinuity aspects are addressed in following Sections 4.1 and 4.2 of this paper and in previous work by the authors [35].

All system and line back up functions (Table 3) were designed and created as a part of the MFLP module. Four main protection segments of the MFLP for each transmission line are depicted in Figure 8.

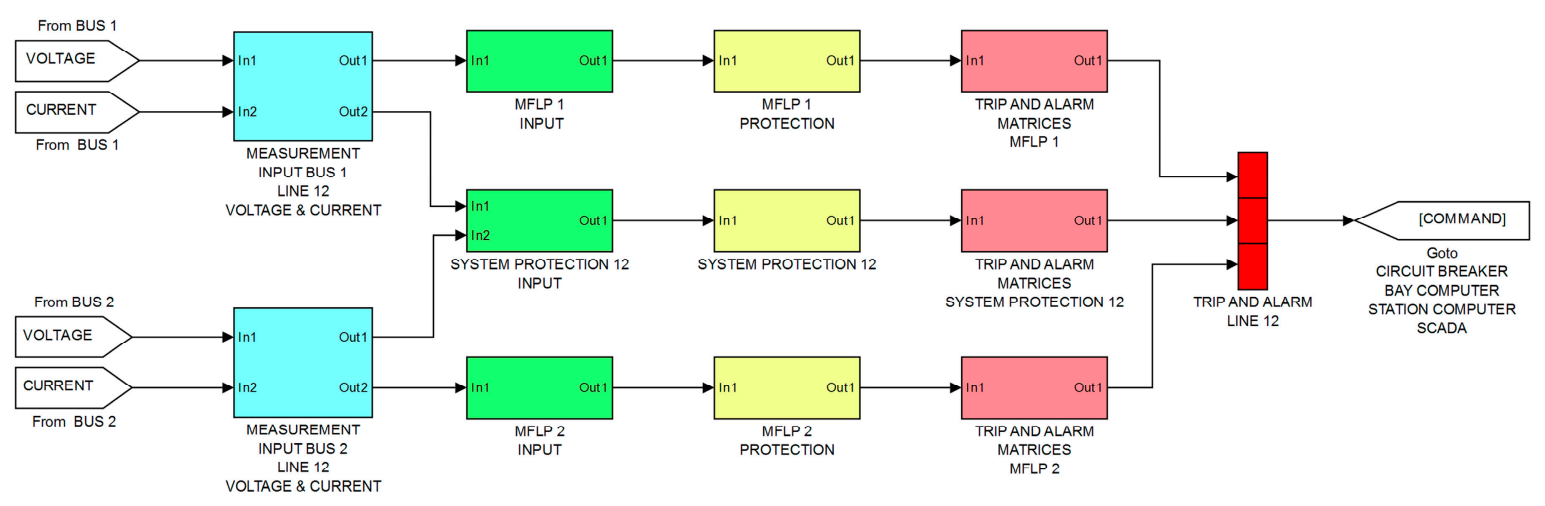

Figure 8. Segments of the developed MFLP model for $400 \mathrm{kV}$ transmission lines in the Matlab environment.

A more detailed scheme with a description of the MFLP can also be found in Appendix A. With the described model a flexible simulation environment for all kinds of protection behavior testing was created. The primary design objective was to realize an environment for protection testing in various system disturbances like active power oscillations and out-of-step conditions. These disturbances are rare events and it is hard to test and compare the global protection response in an online system, therefore highlighting the importance of the developed model. 
In order to improve the functionalities of the WAMPAC system changes are already being done for PMU devices with extended functionality and capability set. New PMU devices will have the following main features (Table 5) according to IEEE C37.118.2 standard that can be used for the development of new protection functions.

Table 5. New phasor measurement unit (PMU) functionalities according to IEEE C37.118.2 standard.

\begin{tabular}{|c|c|c|}
\hline \multirow{2}{*}{ No. } & \multicolumn{2}{|r|}{ PMU Data Package } \\
\hline & Function & Features \\
\hline 1. & Phase values & $U_{\mathrm{L} 1}, U_{\mathrm{L} 2}, U_{\mathrm{L} 3}$ and $I_{\mathrm{L} 1}, I_{\mathrm{L} 2}, I_{\mathrm{L} 3}$ \\
\hline 2. & Symmetrical components & $U_{1}, U_{2}, U_{0}$ and $I_{1}, I_{2}, I_{0}$ \\
\hline 3. & Sampling rate & $\begin{array}{l}20 \mathrm{~ms} \text {, primary Ethernet channel } 100 \mathrm{~ms} \text { secondary } \\
\text { Ethernet channel }\end{array}$ \\
\hline 4. & Frequency & $f, \mathrm{ROCOF}$ (rate of change of frequency) \\
\hline 5. & Binary input & $\begin{array}{l}\text { Circuit breaker status and other information from } \\
\text { switchyard }\end{array}$ \\
\hline 6. & Binary output & Circuit breaker trip command and alarm \\
\hline 7. & Current input & Record of nominal and short circuit current values \\
\hline 8. & Communication channel 1 & $\begin{array}{l}\text { Primary Ethernet channel, with data package divided } \\
\text { into two data streams, IEEE C37.118.2 protocol for PDC1 } \\
\text { and PDC2 }\end{array}$ \\
\hline 9. & Communication channel 2 & $\begin{array}{l}\text { Secondary channel, service port and IEEE C } 37.118 .2 \\
\text { protocol encapsulated in algorithm in order to pull out } \\
\text { phasor data form PMU local memory }\end{array}$ \\
\hline
\end{tabular}

\section{Protection Function Responses}

Angle instability conditions were a primary focus of this paper for researching system protection responses in the developed model. Monitoring voltage angles values (Table 3-No. 1, 2, 3) between line ends is crucial for angle stability protection while the majority of the rest of the values mentioned will be used as direct protection inputs or as an auxiliary parameters.

Setting of the main angle protection function can be obtained using and analyzing simulation results. Tracking the values change and rate of change of electrical values and analyzing these values can lead to the definition of extra protection criteria. Applying additional criteria for protection purposes can aid the detection of breaker switching operations and disturbances.

In the next four sections the characteristic values from disturbance simulations for two selected $400 \mathrm{kV}$ transmission lines between corresponding busbars (Zerjavinec-Tumbri-Melina-Figure 6). The disturbance is simulated on $400 \mathrm{kV}$ line Tumbri-Melina with values presented for the neighboring Zerjavinec-Tumbri $400 \mathrm{kV}$ transmission line. These values from neighboring lines give insight into damping effect through transmission network.

From a relay protection perspective in general there are two groups of disturbances. In the first group are undemanding disturbances for the relay protection system to detect and react like short circuits on lines, transformers or busbars. Other more demanding disturbances for the relay protection system include system-wide disturbances like power swing and out-of-step conditions. Both types of disturbances were studied. All events and disturbances were precisely followed and traced during a $10 \mathrm{~s}$ simulation period. The results are used to parametrize and adjust the protection system settings.

\subsection{Normal Operating Condition in Transmission Network}

Monitoring normal operation with PMU data in a MFLP module provides valuable insight into the transmission conditions. Almost all switching operations during normal and regular network 
operations can be traced. A very accurate footprint can be generated. Relatively small changes in the observed angle values can be recorded and recognized with the MFLP algorithm. That small change in angle difference and ROCOA is depicted in Figure 9.

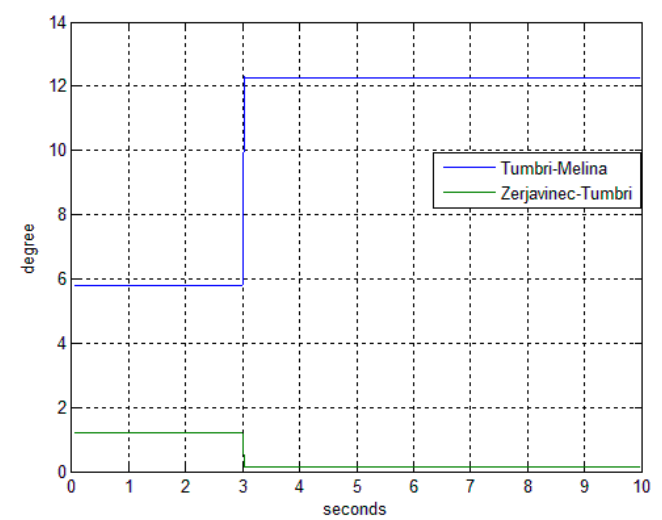

(a)

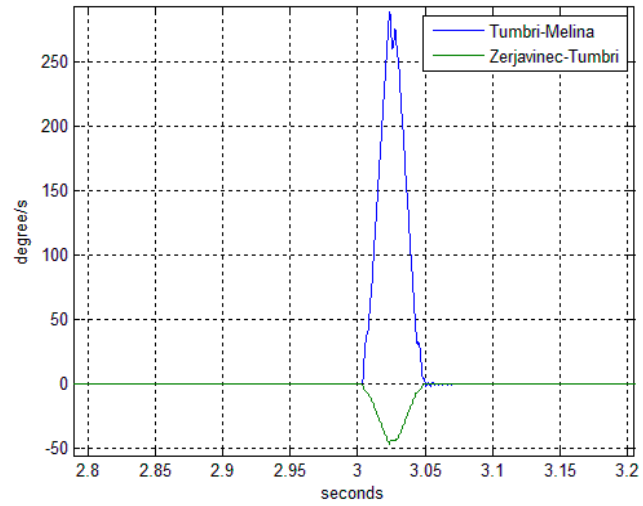

(b)

Figure 9. Phase angle values measured on two transmissions lines under normal loading conditions during regular switching operation on the Tumbri-Melina line (circuit breaker opening at the Tumbri substation). (a) Phase angle difference $\Delta \varphi$; (b) Angle speed (rate of change of angle (ROCOA)).

Angle acceleration changes (Figure 10a) are presented for two lines for normal loading conditions during the event of disconnection from operation of the $400 \mathrm{kV}$ Tumbri-Melina line. It can be clearly seen that the change values are significantly higher on the line where the circuit breaker operated (Tumbri-Melina). Nevertheless the same event can be detected on the neighboring line that remains in operation, which demonstrates the possibility of also tracing events in a transmission network during normal operating conditions. The same trend can be followed for additional values, e.g., voltage changes (Figure 10b).

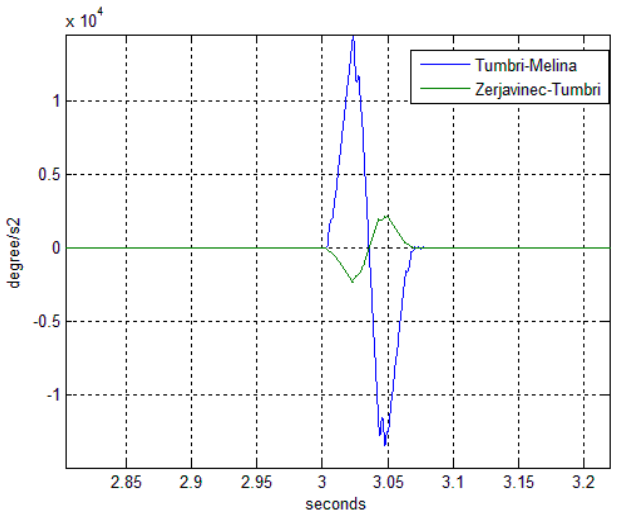

(a)

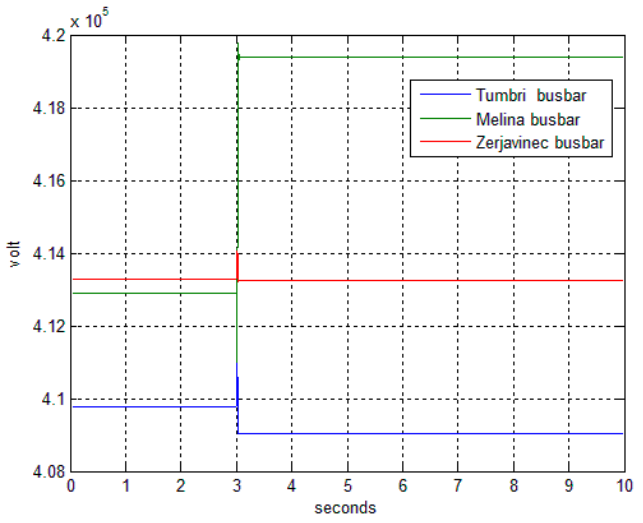

(b)

Figure 10. Values measured on two transmissions lines under normal loading conditions during regular switching operations on the Tumbri-Melina line (circuit breaker opening at the Tumbri substation).

(a) Angle acceleration on both lines; (b) Voltage values from three busbars.

These small changes in values can be also be traced by overlapping the three corresponding busbar voltages to detect the source of the change. Additional values that can be used in a similar way are active and reactive power values measured on the one or both line ends (Figure 11) where a distinctive difference can be seen. 


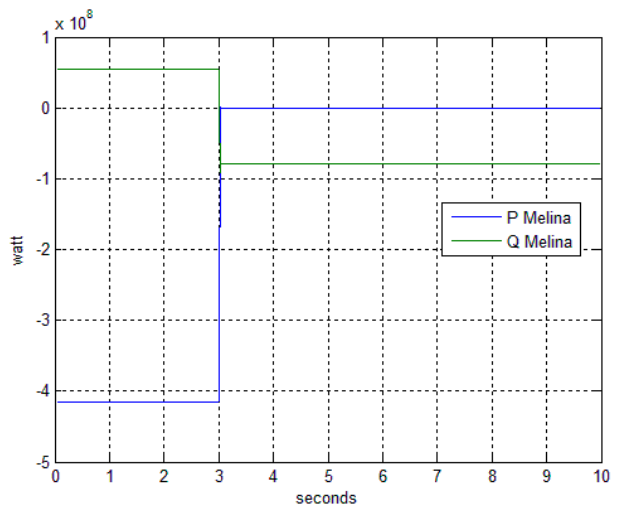

(a)

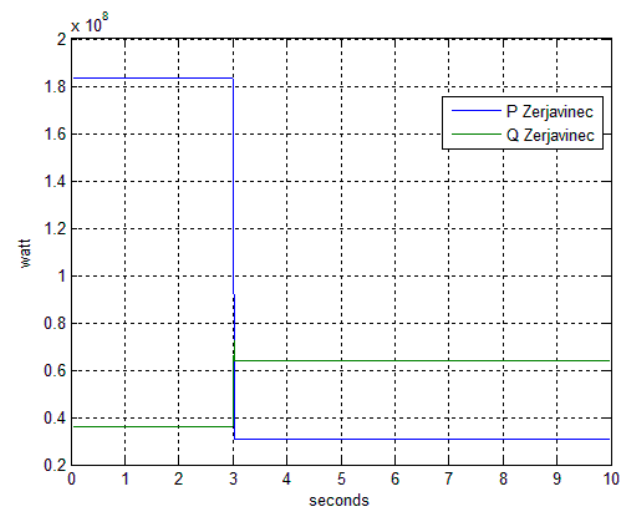

(b)

Figure 11. Changes in power flow on two transmissions lines under normal loading conditions during regular switching operation on the Tumbri-Melina line (circuit breaker opening at the Tumbri substation). (a) Active and reactive power flow measured from the $400 \mathrm{kV}$ Melina substation; (b) Active and reactive power flow measured from the $400 \mathrm{kV}$ Zerjavinec substation.

Power values also represent valuable additional indication that a certain event occurred. It can be overlapped with other values to support the decisions. On that basis an algorithm for recognition of circuit breaker operations is designed. Data analyses from the WAM system implemented in the control center showed tracking is possible through the whole network and for different transmission voltage levels. Those indications are useful in the recognition process of circuit breaker operations. In that sense almost every breaker operation on the transmission network observed with PMU devices can be clearly caught with PMU data independently from the status signal indicator of the circuit breaker.

\subsection{Short Circuit Conditions on Transmission Lines}

Disturbances like short circuits in the transmission network are common and can be entirely monitored and observed with data generated from PMU devices with characteristics described in Table 3. Characteristic values behavior in transmission network in those conditions are presented.

Compared to normal operation (Figure 9) all angle values are significantly higher (Figure 12). The disturbances have a characteristic footprint manifested through a strong distortion of voltage and current in a short period of time on a line affected by a fault. Total fault clearing time is only a few $50 \mathrm{~Hz}$ periods (60 to 80 milliseconds). Event time horizon can be split into four main segments. The first and last segments have the same values. The second segment includes a high increase of values until the circuit breaker opens on both line sides and the auto reclose sequence starts. Then in the third segment, due to the dead time of the auto reclose sequence, the angle difference between busbars is constant but has new values because the line was disconnected. In the last segment after closing of the breakers the regular values of the angle difference are restored. A similar trend can be observed for angle acceleration and busbar voltage values (Figure 13). Two important conclusions can be drawn:

(1) The indication of location where the fault occurs only based on angles values points to the fact that the DO is near the Tumbri substation (according to Equation (23)).

(2) The fact that circuit breaker closing can be detected and traced is based on the very high angle acceleration values during this short lasting event. That event is pinpointed from the values of ROCOA (Figure 12b) and angle acceleration (Figure 13a), after the closing command from the auto-recloser sequence. Additional criteria for DO location (Equation (23)) are busbar voltages (Figure 13b). The lowest value is measured near the Tumbri substation. Voltage values are higher at the Melina substation then at the Zerjavinec substation because of the damping effect since the Tumbri-Melina line is more than twice longer. Angles values on other transmission lines have 
insignificant values compared to the faulty line. The voltage drop pattern in the transmission network for this disturbance is typical and can be observed on all transmission lines.

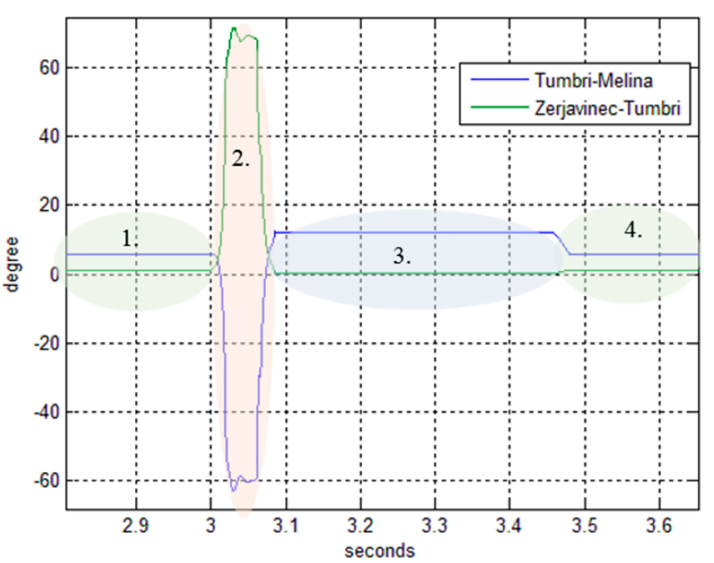

(a)

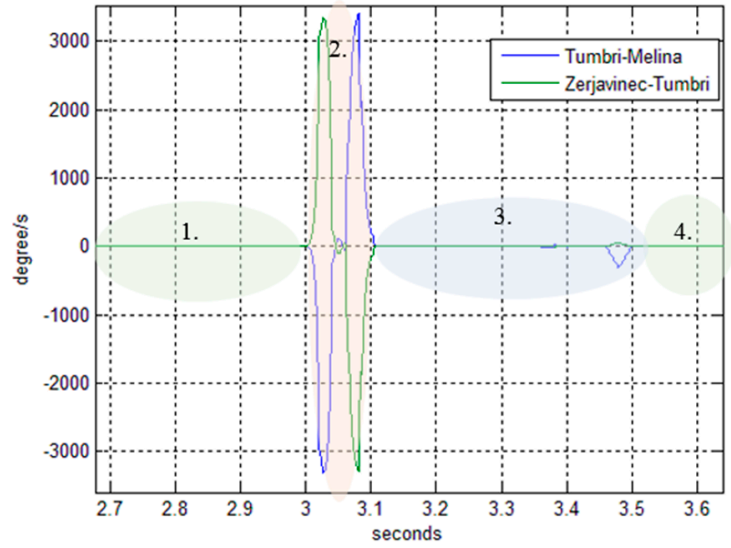

(b)

Figure 12. Phase values on two transmission lines with a three phase short circuit (breakers on this line were opened and closed during an auto reclose sequence) near the $400 \mathrm{kV}$ Tumbri substation on the 400 kV Tumbri-Melina line. (a) Angle difference $\Delta \varphi$; (b) Angle speed (ROCOA).

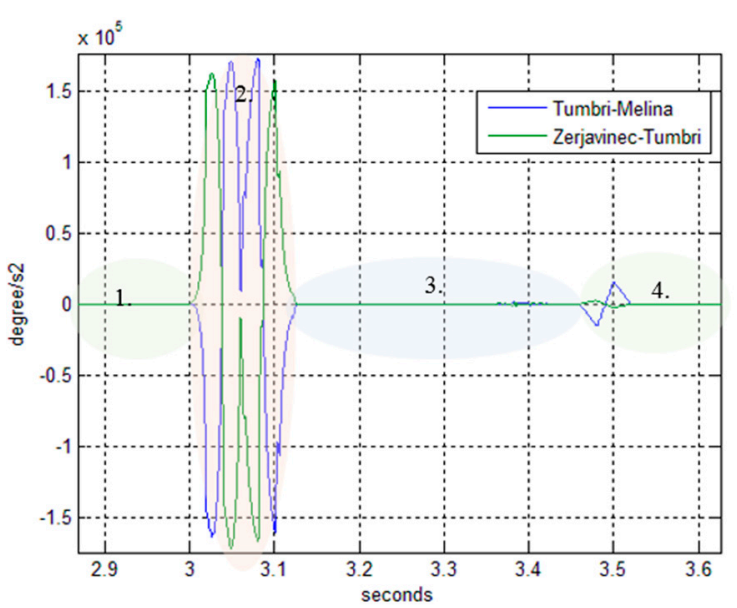

(a)

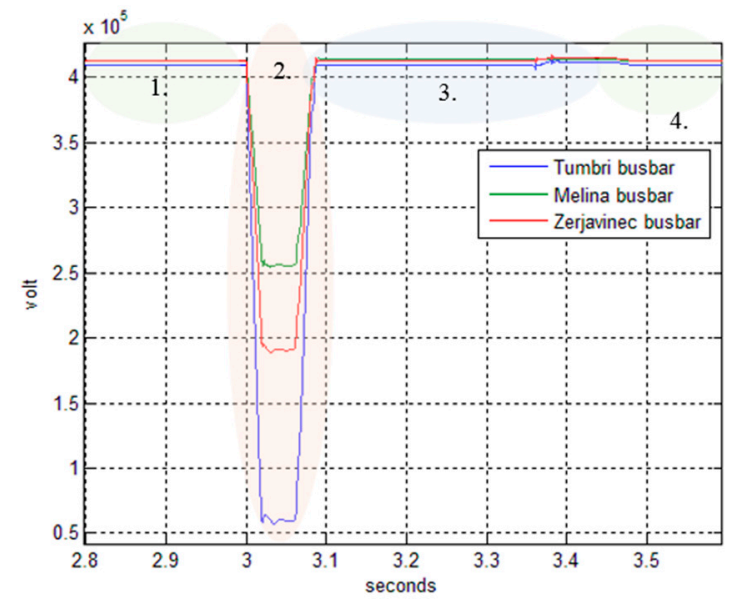

(b)

Figure 13. Values measured from two transmission lines with a three phase short circuit (breakers on this line were opened and closed during the auto reclose sequence) near the $400 \mathrm{kV}$ Tumbri substation on the $400 \mathrm{kV}$ Tumbri-Melina line. (a) Angle acceleration on both lines; (b) Voltage values from three busbar.

Busbar faults generate a similar pattern behavior like transmission line faults but for precise detection an extra criterion is needed (line differential function). The differential protection can detect various kinds of faults if the right measurement is available since the current patters are unique for every type and location of a corresponding fault. The current pattern for a fault simulated on the Tumbri-Melina line (Figure 14a) and the neighboring Zerjavinec-Tumbri line (Figure 14b) is presented. The values presented on the graphs have different $y$-axis values. The line differential function localized the fault locations on the Tumbri-Melina line. The neighboring line has negligible values for the line differential current. The line currents have almost the same values and there is an overlap of curves on Figure 14b. Small values are a consequence of the line charging current and do not represent an obstacle for the developed algorithm. 


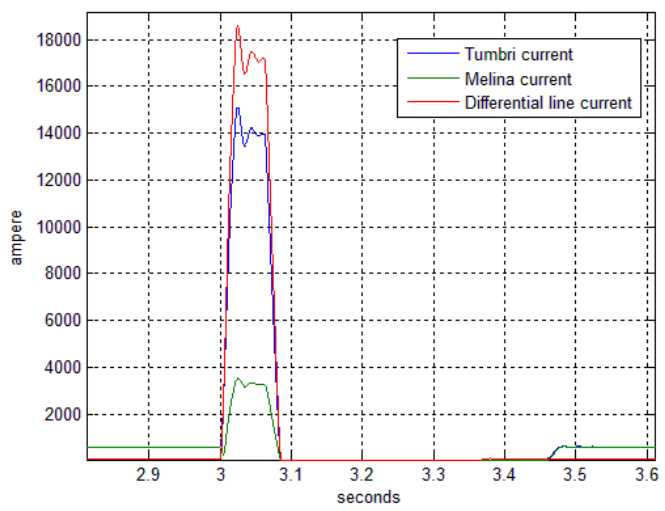

(a)

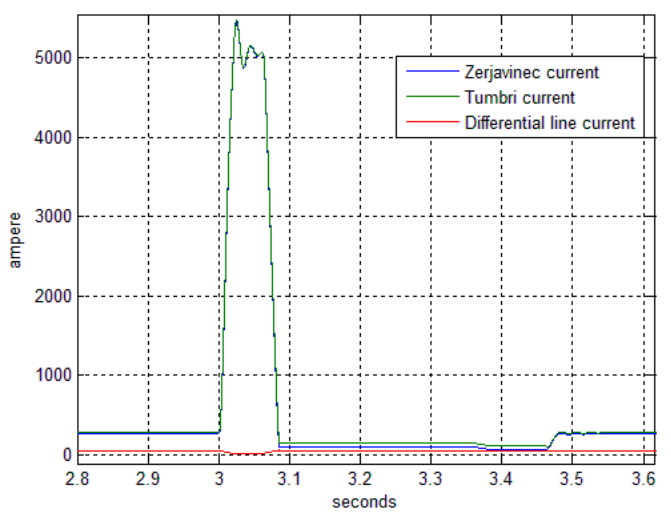

(b)

Figure 14. Current values measured from two transmission lines with three phase short circuit (breakers on this line were opened and closed during an auto reclose sequence) near the Tumbri substation on the $400 \mathrm{kV}$ Tumbri-Melina line. (a) Line currents from both line ends and differential current on the $400 \mathrm{kV}$ Tumbri-Melina line; (b) Line currents from both line ends and differential current on the $400 \mathrm{kV}$ Zerjavinec-Tumbri line.

Rate of change of the current can be used as an additional criterion for detection and location of a short circuit in the transmission network (Figure 15). The faulty line demonstrated extremely high values of the current change rated compared to other lines. Values are the same for neighboring lines and therefore the current values overlap on Figure $15 \mathrm{~b}$.

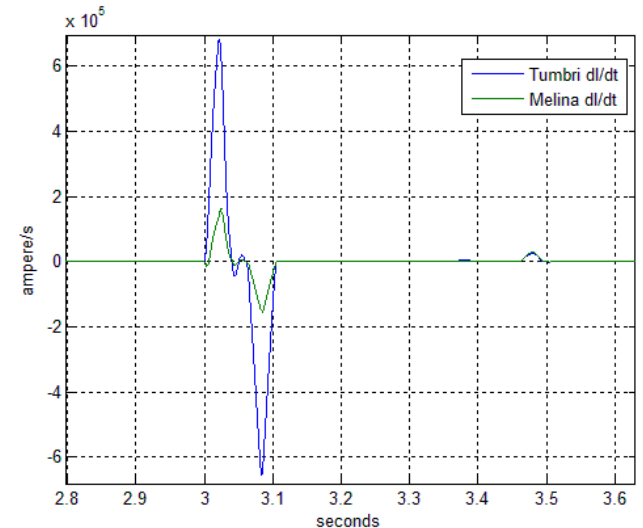

(a)

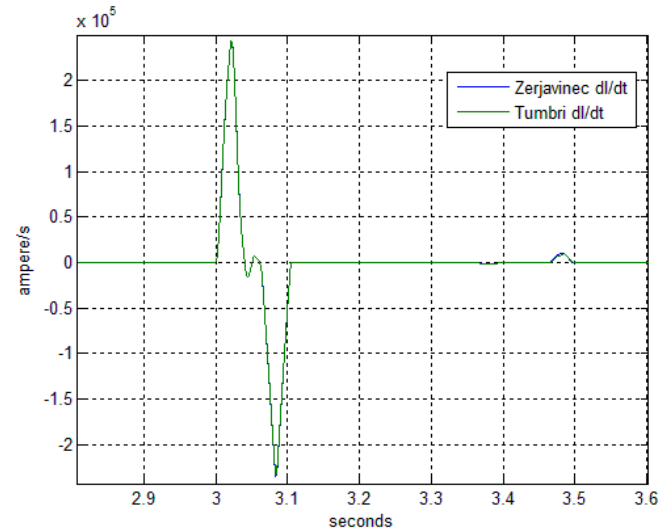

(b)

Figure 15. Rate of change of current values measured from two transmission lines with a three phase short circuit (breakers on this line were opened and closed during an auto reclose sequence) near the Tumbri substation on the $400 \mathrm{kV}$ Tumbri-Melina line. (a) Rate of change of currents from both line ends for the $400 \mathrm{kV}$ Tumbri-Melina line; (b) Rate of change of currents from both line ends on the $400 \mathrm{kV}$ Zerjavinec-Tumbri line.

\subsection{Power Swing Conditions in Transmission Networks}

Active power oscillations or power swings in the transmission network were the focus of the research described in this paper. This phenomena is very challenging for real time detection and protection in meshed transmission networks. Modern MFLP modules have the ability to cover alarming issues, trace DO and properly react using PMU data. As was presented in previous sections (Sections 4.1 and 4.2) tracing of all three angles values has great potential for out-of-step-protection in WAMPAC applications. 
An out-of-step disturbance is a version of angle instability and has its own characteristic footprint. Angle instabilities (e.g., power swings) are not as localized as it was the case with circuit breaker operations or short circuit faults. Oscillations can appear or propagate from anywhere in the wider transmission system or generator unit. Oscillations propagate through whole network with a certain damping effect. Power swing disturbances can last for a certain period of time [44] if local protection systems do not react. The goal of the MFLP module if an out-of-step disturbance has a small oscillation compared to the line rated power is to generate an alarm together with the indications of DO while leaving action decisions to the operational crew in the control center. If oscillations exceed some preset threshold value a tripping command is generated by the MFLP module and a reaction is assured. Measurements in the vicinity of the DO record larger deviations across all measured system values. The damping effect through the transmission network reduced deviations in electrical values as was mentioned already. Simulations results were presented for the Tumbri-Melina line and the neighboring Zerjavinec-Tumbri line. Figure 16 shows the characteristic footprints for intensive power swings near a disturbance source in the Melina substations for the angle perspective (Figure 16a) and rate of change of angle (Figure 16b). Both measured values are exposed to strong oscillations on the line closer to the DO which pinpoints the DO at the $400 \mathrm{kV}$ Melina substation.

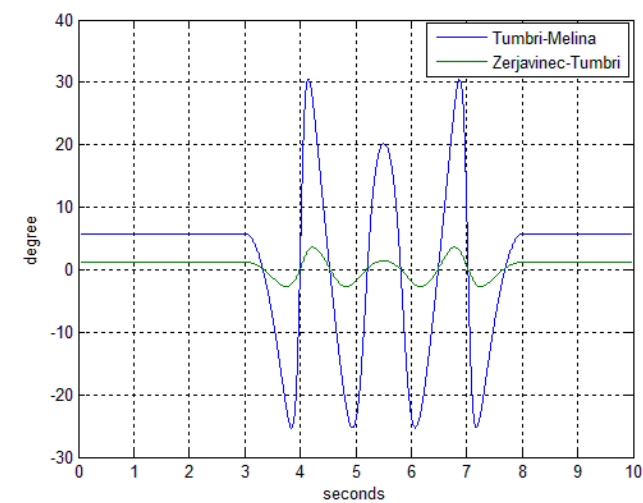

(a)

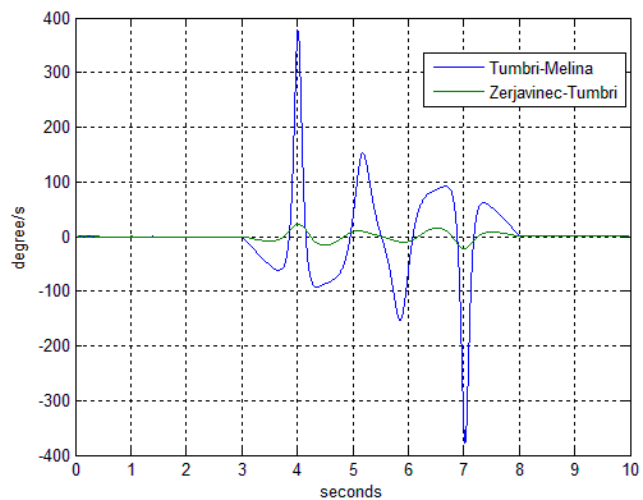

(b)

Figure 16. Phase values on two $400 \mathrm{kV}$ transmission lines during power swing conditions in a transmission network (source of the active power oscillation was at the $400 \mathrm{kV}$ Melina substation). (a) Values for phase angle difference $\Delta \varphi$; (b) Values for ROCOA.

A similar pattern is valid for angle acceleration (Figure 17a). Monitoring of these values can be a reliable pointer to elements in the transmission network where the disturbance originates Voltage values on the busbar in three substations also give valuable insight into conditions during such system disturbances (Figure 17b).

The largest voltage drop occurs at the Melina substation and from there oscillations propagate through the whole network. Additional criteria can be created with power value measurements (active and reactive). These additional criteria for protection purposes can be created with the values of active and reactive power change. Tripping criteria can be supplemented with the measurements of rate of change of power (Figure 18). Higher changes are detected on line nearest to the source of oscillations. Tracking the change and rate of change of electrical values and analyzing these values can lead to the definition of extra protection criteria. 


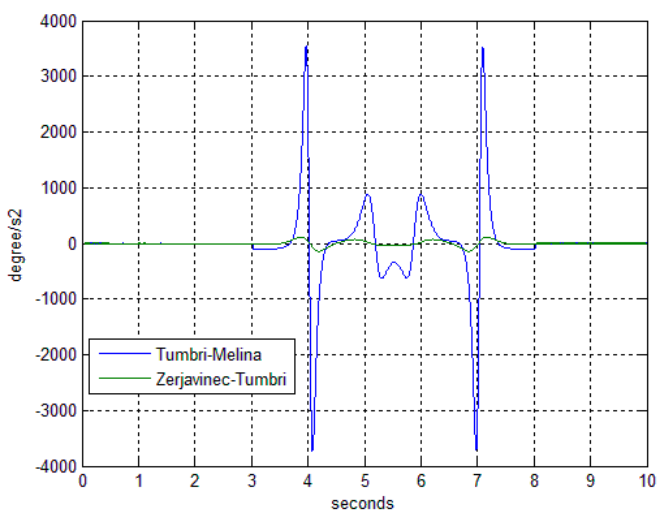

(a)

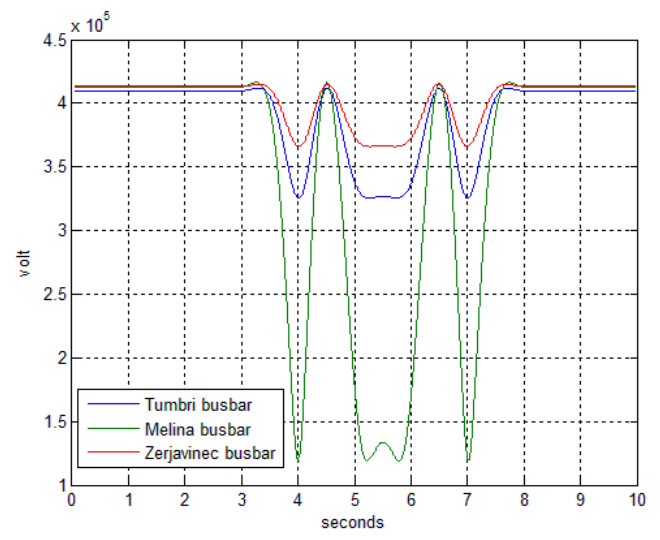

(b)

Figure 17. Values measured from two transmission lines during power swing conditions in a transmission network (the source of the active power oscillations is at the $400 \mathrm{kV}$ Melina substation). (a) Angle acceleration; (b) Voltage values from three busbars.

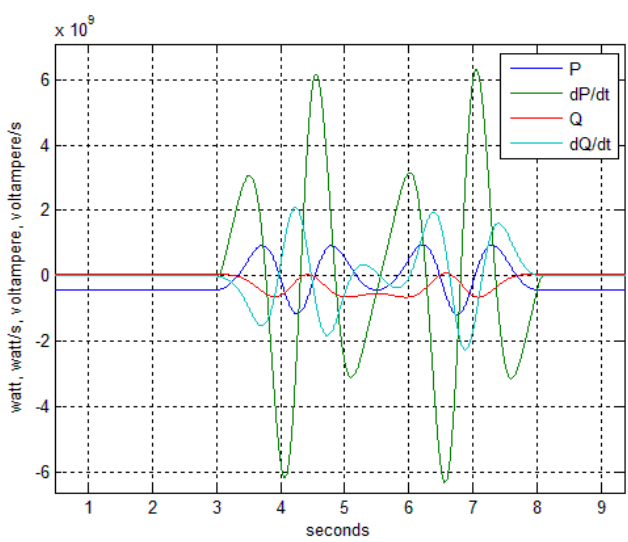

(a)

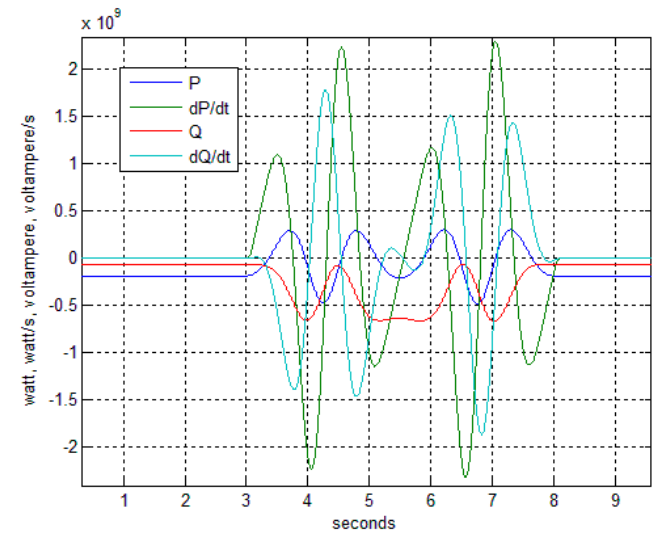

(b)

Figure 18. Changes in active and reactive power (active power, rate of change of active power, reactive power and rate of change of reactive power) during power swing conditions in a transmission network (the source of the active power oscillations is at the Melina substation) on two neighboring lines.

(a) Values for the $400 \mathrm{kV}$ Tumbri-Melina line; (b) Values for $400 \mathrm{kV}$ Zerjavinec-Tumbri line.

Power swings can in some cases develop into much more serious events, out-of-step conditions disturbances, and because of this power swings in transmission network must be observed, traced and reacted to in a proper time frame.

\subsection{Out-of-Step Conditions in Transmission Networks}

The most severe stage of angle instability is out-of-step condition. It can develop from active power oscillations in a transmission network or from some sudden events. The MFLP module was designed to have the capability of proper reaction using PMU data. These protection functions depend mainly on angle values with the support of additional criteria.

Out-of-step disturbances also have characteristic patterns. All measured values reach very high amplitudes like short circuit conditions, but in the case of out-of-step conditions such high values can last much longer. Actions of traditional relay protection systems always have a delay in their reaction but the developed MFLP module using PMU measurements is able to react in an extremely short period before the first slip happens $\left(\varphi \geq 180^{\circ}\right)$. 
Another $400 \mathrm{kV}$ substation was chosen (Zerjavinec instead of Melina) for this out-of-step condition simulation series. The $400 \mathrm{kV}$ Ernestinovo substation has four international interconnection tie lines and it is assumed that such a serious disturbance will be imported from the external transmission network and that the source will not be inside the smaller test system that was modelled in detail. Active power oscillations were initiated at the $400 \mathrm{kV}$ Ernestinovo substation and a consequence was out-of-step conditions occurring on the $400 \mathrm{kV}$ Ernestinovo-Zerjavinec transmission line. The neighboring $400 \mathrm{kV}$ Zerjavinec-Tumbri line is exposed to the power swing only as will be shown in the following figures (Figures 19-22).

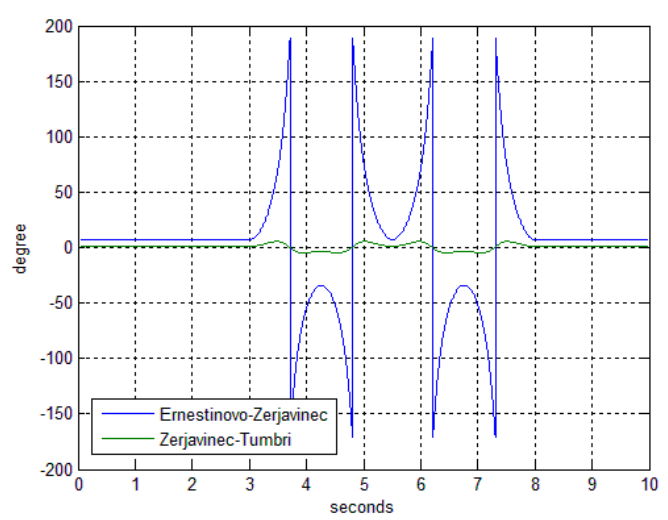

(a)

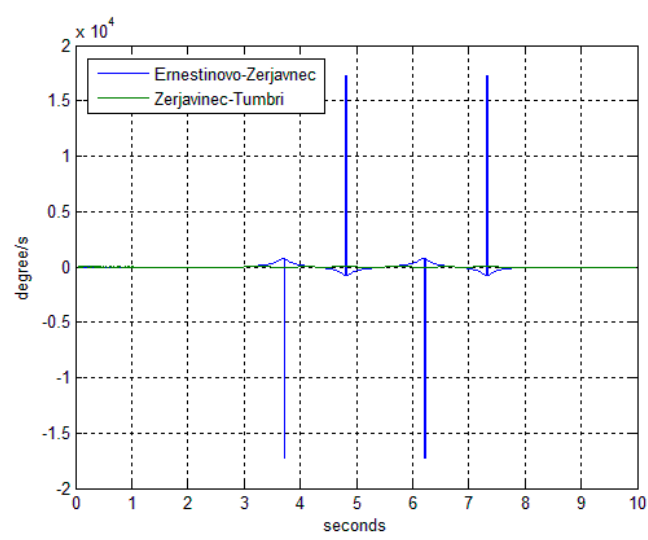

(b)

Figure 19. Phase values on two transmission lines during out-of-step conditions in a transmission network (the source of the active power oscillations was at the $400 \mathrm{kV}$ Ernestinovo substation). (a) Phase angle difference $\Delta \varphi ;(\mathbf{b})$ ROCOA.

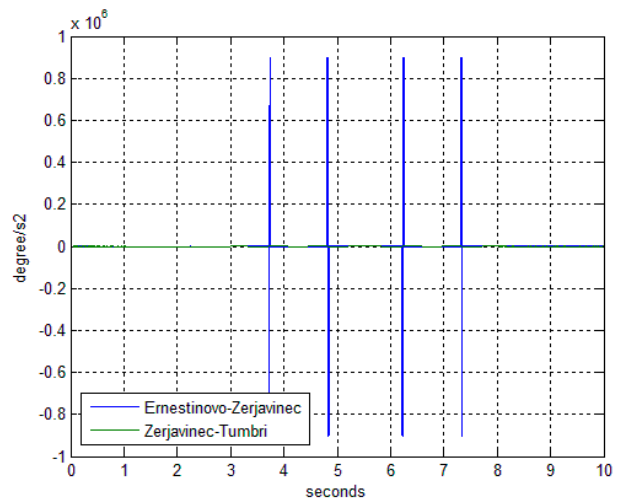

(a)

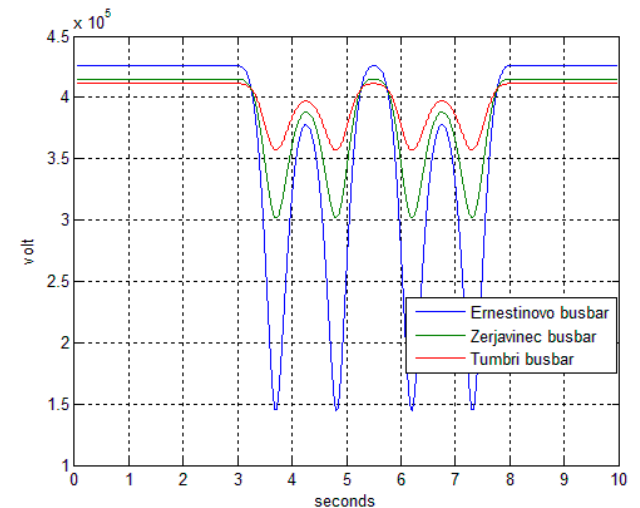

(b)

Figure 20. Values measured from two transmission lines during out-of-step conditions in a transmission network (the source of the active power oscillations was at the $400 \mathrm{kV}$ Ernestinovo substation). (a) Angle acceleration; (b) Voltage values from three busbars. 


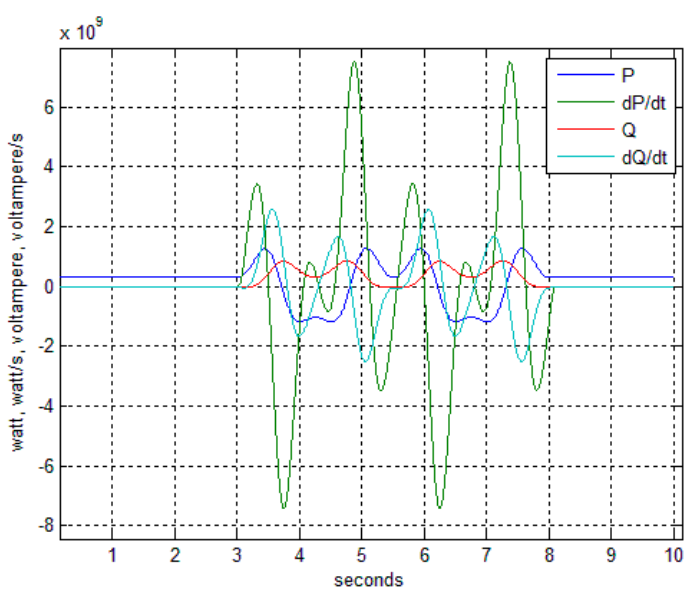

(a)

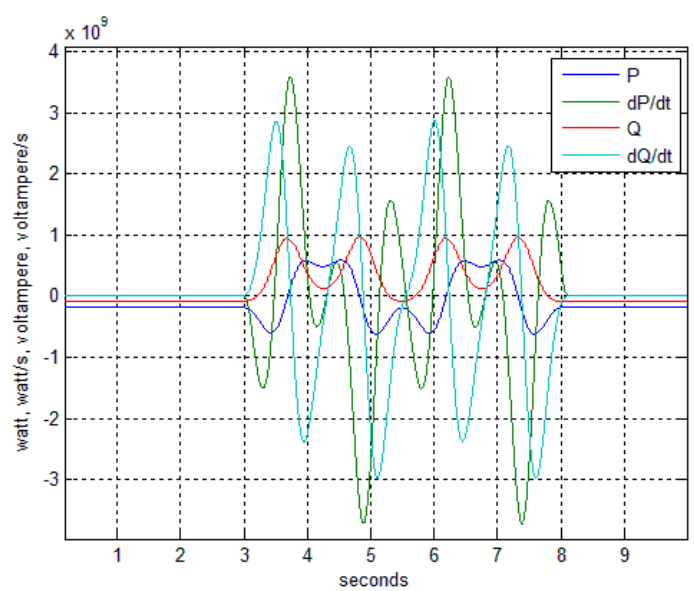

(b)

Figure 21. Changes in active and reactive power, rate of change of active power, rate of change of reactive power during power swing conditions in a transmission network. The source of the active power oscillations was at the Ernestinovo substation. (a) Values near the disturbance source at the Ernestinovo substation for the Ernestinovo-Zerjavinec line; (b) Values near the disturbance source at the Ernestinovo substation for the neighboring Zerjavinec-Tumbri line.

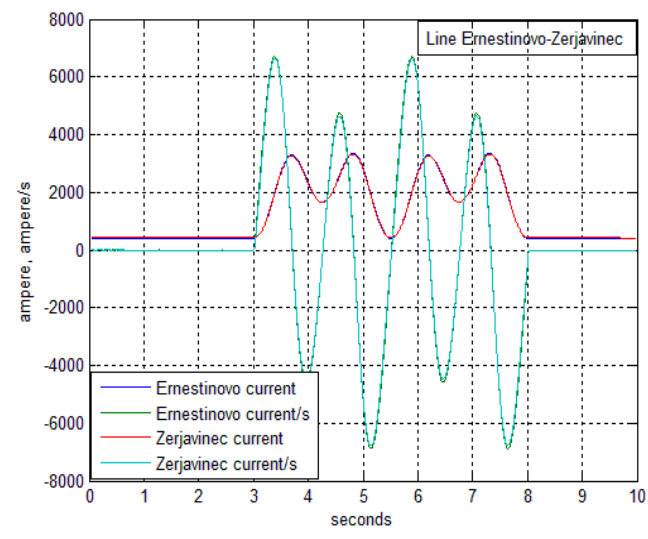

(a)

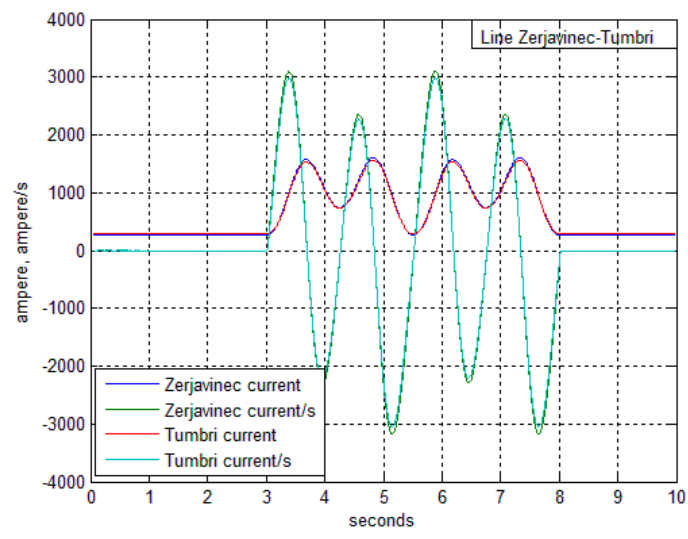

(b)

Figure 22. Current and rate of change of current values measured from two transmission lines (currents measured on both line ends) for out-of- step conditions with the oscillations source near the $400 \mathrm{kV}$ Ernestinovo substation. (a) Current and rate of change of currents from both line ends for the Ernestinovo-Zerjavinec line; (b) Current and rate of change of currents from both line ends on the Zerjavinec-Tumbri line.

Angle dynamics clearly show the development of the out-of-step condition when the angle difference $\Delta \varphi$ reaches $180^{\circ}$ on the Ernestinovo-Zerjavinec line (Figure 19). At that moment (the angle difference reaches $180^{\circ}$ ) a slip occurs (Figure 19a) and the angle velocity has extremely high values (Figure 19b). The MFLP module with the proposed algorithm can detect and react accordingly to this out-of-step disturbance.

In the developed transmission model out-of-step conditions occur just on one $400 \mathrm{kV}$ transmission line (Ernestinovo-Zerjavinec). Adjacent lines have significantly smaller oscillations and even farther away the transmission lines have even more damped oscillations. First the neighboring $400 \mathrm{kV}$ Zerjavinec-Tumbri line undergoes only power oscillations. The angle acceleration, along the other two angle values of phase difference and ROCOA, has very high values for the line affected by this disturbance (Figure 20a). The voltage pattern provides insight into the voltage decrease propagation 
through the network (Figure 20b). The biggest voltage drop occurs at the $400 \mathrm{kV}$ Ernestinovo substation. The angle and voltage dynamics depicted in Figure 20, indicate that there is an oscillation source at the $400 \mathrm{kV}$ Ernestinovo substation.

Active and reactive power oscillations and rate of change of these values are also measured (Figure 21) in the proposed protection system. This data gives valuable information about the disturbance and its propagation through the transmission system.

Additional criteria for protection purposes can be derived from those values. Alarming logic for detecting power oscillations can use this data. Another useful dataset being measured are the current values (Figure 22). These can be helpful for selectivity protection criteria. The Ernestinovo-Zerjavinec line affected by out-of-step conditions has higher oscillation values than the other line (the $y$-axis values are different). Current measurements for both line ends have almost identical values and therefore the lines in Figure 22 are overlapped.

\section{Conclusions}

All transmission network conditions and disturbance can be monitored, observed and identified with PMU measurements at ones disposal. The intention of this research was to utilize phasor data in a way that captures power system dynamic phenomena enabling advanced system protection schemes in future WAMPAC systems at transmission network control centers.

The process of designing a WAMPAC system is complex and is divided into phases. In the starting phase a conceptual solution is developed. During that phase various analyses and simulations were carried out with selected important ones being presented in the paper. In the second phase phasor data is used for different protection purposes such as the multifunctional line protection (MFLP) application described in this paper. The developed MFLP system has the scope and functionality of both backup protection functions and system protection functions.

The MFLP module and accompanying protection algorithm as a part of a WAMPAC system are presented. Out-of-step conditions are critical events for transmission power networks. The time domain of angle instability, more specifically out-of-step conditions, is in the milliseconds range and therefore the remaining reaction time is no more than 200 milliseconds. Fast and quality phasor measurement data streams can be used to establish an angle prediction algorithm. The proposed central protection MFLP module uses PMU measurements and has the ability to prevent first slip during out-of-step disturbances by issuing a trip command to the circuit breaker before the out-of-step conditions occurs. Additionally, such MFLP functionality enables full observability of relay protection system operations at the control center.

The presented protection algorithm was developed in the Matlab simulation environment alongside a test $400 \mathrm{kV}$ transmission network and the corresponding protection system. All data streams required for data acquisition were also implemented. The developed transmission network model was subjected to a comprehensive validation and verification process using a broad range of archived data. The results of the characteristic simulation were presented to demonstrate the operation of MFLP reacting to specific disturbances like normal breaker switching operations, short circuit faults and heavy active power oscillations (powers swings and out-of-step conditions). The simulations show a distinctive pattern difference between the various events and recognize key characteristics that can be used to detect and locate the disturbances in a transmission system.

The presented work is based on a 6-bus system and in an online server test developed back-up line protection function performed well and reacted in a time frame smaller than 100 milliseconds. For a larger scale system that could consist of thousands of nodes division into control and protection zones would be required in order to implement a similar PMU protection algorithm. This will be the focus of our future work that will be continued in order to obtain the key performance indices for two basic operation conditions-normal breaker operations and disturbance events. Indices obtained in that manner can be used for setting parameters, including alarm levels and protection reaction levels, 
in different protection modules. Furthermore, the design of algorithms for system disturbances like voltage instability and frequency instability will be analyzed.

Acknowledgments: This work has been supported in part by the Croatian Science Foundation under the project FENISG-Flexible Energy Nodes in Low Carbon Smart Network (Grant No. 7766) and Croatian Science Foundation and Croatian TSO (HOPS) under the project SIREN-Smart Integration of RENewables (Grant No. I-2538-2015).

Author Contributions: Igor Ivanković and Igor Kuzle conceived and designed the experiments; Ninoslav Holjevac contributed to analysis tools design; Igor Ivanković performed the experiments; Igor Ivanković and Igor Kuzle analyzed the data; Igor Ivanković, Ninoslav Holjevac and Igor Kuzle wrote the paper.

Conflicts of Interest: The authors declare no conflict of interest.

\section{Appendix A}

The first segment in the MFLP module is a measurement input part (blue shaded area in Figure A1). It collects phase current and voltage measurements from line ends (bus 1 and bus 2) and creates a phasor data stream with positive voltage and current components. The phase values for voltage, current and power are created, $(U, I, P$ and $Q$ values) for monitoring purposes.

Further, the protection system input is created to build up protection algorithms for all functions from Table 3. Other necessary measurements are extracted from the phasor data stream, such as $Z$, $R, X, P$ and $Q$ values (light green shaded area in Figure A1). These parts in the MFLP module have transmission line protection functionality in order to create line backup protection and additional criteria for WAMPAC.

The third part consists of protection settings and tripping criteria (light yellow shaded area of Figure A1). These segments of the system protection module have the functionality for detecting system disturbance on each transmission line. In that part polygonal characteristics for distance protection purposes are created. Line backup protection has key transmission protection functionality used in transmission system operations.

The last parts are the tripping matrices for line circuit breaker switching (light red shaded area in Figure A1). Additionally, alarms from all protection and monitoring functions can be generated and connected to a SCADA system located in the central control center. 


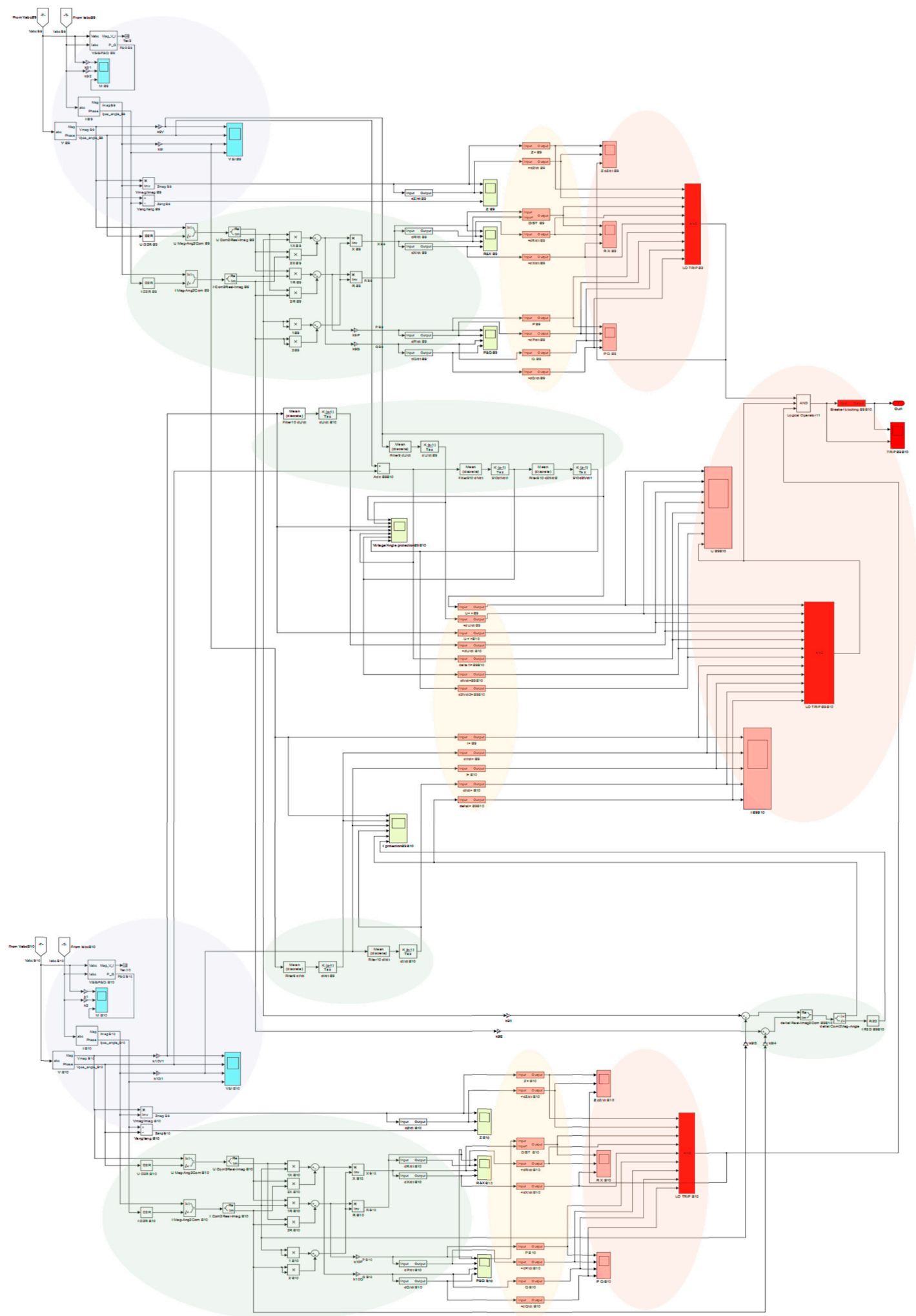

Figure A1. Details of the developed MFLP Matlab model. 


\section{References}

1. Jin, T.; Chu, F.; Ling, C.; Nzongo, D.L.M. A Robust WLS Power System State Estimation Method Integrating a Wide-Area Measurement System and SCADA Technology. Energies 2015, 8, 2769-2787. [CrossRef]

2. Terzija, V.; Valverde, G.; Cai, D.; Regulski, P.; Madani, V.; Fitch, J.; Skok, S.; Begovic, M.M.; Phadke, A. Wide area monitoring protection control of future electric power networks. IEEE Proc. 2011, 99, 80-93. [CrossRef]

3. Hong, X. A Total Solution for Power Network Monitoring and Controlling-WAMAP. In Proceedings of the 2007 IEEE Power Engineering Society General Meeting, Tampa, FL, USA, 24-28 June 2007; pp. 1-6.

4. Perkov, M.; Baranović, N.; Ivanković, I.; Višić, I. Implementation strategies for migration towards smart grid. In Proceedings of the Powergrid Europe 2010, Conference \& Exhibition, Amsterdam, The Netherlands, 8-10 June 2010.

5. Baranovic, N.; Andersson, P.; Ivankovic, I.; Zubrinic-Kostovic, K.; Peharda, D.; Larsson, J.E. Experiences from Intelligent Alarm Processing and Decision Support Tools in Smart Grid Transmission Control Centers. In Proceedings of the CIGRÉ Session 46, Paris, France, 21-26 August 2016. Paper D2-112.

6. Novosel, D. Phasor Measurement Application Study; Final Project Report; California Institute for Energy and Environment (CIEE), University of California: Berkeley, CA, USA, 2007.

7. De La Ree, J.; Centeno, V.; Thorp, J.S.; Phadke, A.G. Synchronized Phasor Measurement Applications in Power Systems. IEEE Trans. Smart Netw. 2010, 1, 20-27. [CrossRef]

8. Stojsavljević, M.; Nemec, D.; Ivanković, I. WAMS in Croatian Power System. In Proceedings of the 2nd International Conference on Monitoring of Power System Dynamics Performance, Saint Petersburg, Russia, 28-30 April 2008; pp. 1-8.

9. Wang, Y.; Tang, Y.; Ding, L.; Zhang, C.; Chen, Z.; Huang, Y. A Wide-area Coordinated Out-of-step Control System. In Proceedings of the International Conference on Power System Technology (POWERCON 2014), Chengdu, China, 20-22 October 2014; pp. 691-695.

10. Ivankovic, I.; Kuzle, I.; Holjevac, N. Multifunctional WAMPAC system concept for out-of-step protection based on synchrophasor measurements. Int. J. Electr. Power Energy Syst. 2017, 87, 77-88. [CrossRef]

11. Wang, Y.; Jin, W.; Ke, S.; Chen, Y.; Ma, J. A novel method for locating power system out-of-step center on the basis of oscillation energy flow. In Proceedings of the 2016 IEEE PES Asia-Pacific Power and Energy Conference, Xi'an, China, 25-28 October 2016.

12. Brahma, S.M. Distance relay with out-of-step blocking function using wavelet transform. IEEE Trans. Power Deliv. 2007, 22, 1360-1366. [CrossRef]

13. Yaghobi, H. Out-of-step protection of generator using analysis of angular velocity and acceleration data measured from magnetic flux. Electr. Power Syst. Res. 2016, 132, 9-21. [CrossRef]

14. Sauhats, A.; Utans, A.; Antonovs, D.; Svalovs, A. Angle Control-Based Multi-Terminal Out-of-Step Protection System. Energies 2017, 10,1-16. [CrossRef]

15. Schweitzer, E.O.; Whitehead, D.E.; Guzman, A. Real-Time Power System Control Using Synchrophasors. In Proceedings of the 10th Annual Automation and Integration Seminar at WPDAC, Spokane, WA, USA, 7 April 2008.

16. Zbunjak, Z.; Kuzle, I. Advanced control and system integrity protection schemes of Croatian power transmission network with integrated renewable energy sources. In Proceedings of the IEEE EUROCON, Zagreb, Croatia, 1-4 July 2013; pp. 706-711.

17. MATLAB. Available online: https://uk.mathworks.com/products/matlab.html (accessed on 24 April 2017).

18. Ivankovic, I.; Kuzle, I.; Sirovina, R. Multifunctional System Protection for Transmission Lines Based on Phasor Data. In Proceedings of the IEEE 16th International Conference on Environment and Electrical Engineering (EEEIC), Florence, Italy, 7-10 June 2016; pp. 1-6.

19. Ivanković, I.; Rubeša, R.; Kuzle, I. Modeling 400 kV Transmission Grid with System Protection and Disturbance Analysis. In Proceedings of the IEEE International Energy Conference-Energycon 2016, Leuven, Belgium, 4-8 April 2016; pp. 1-7.

20. Zhang, S.; Zhang, Y. A Novel Out-of-Step Splitting Protection Based on the Wide Area Information. IEEE Trans. Smart Grids 2017, 8, 41-51. [CrossRef]

21. Alinezhad, B.; Karegar, H.K. Out-of-Step Protection Based on Equal Area Criterion. IEEE Trans. Power Syst. 2017, 32, 968-977. [CrossRef] 
22. Li, M.; Pal, A.; Phadke, A.G.; Thorp, J.S. Transient stability prediction based on apparent impedance trajectory recorded by PMUs. Int. J. Electr. Power Energy Syst. 2014, 54, 498-504. [CrossRef]

23. Rovnyak, S.M.; Taylor, C.W.; Sheng, Y. Decision Trees Using apparent Resistance to Detect Impending Loss of Synchronism. IEEE Trans. Power Deliv. 2000, 15, 1157-1162. [CrossRef]

24. So, K.H.; Heo, J.Y.; Kim, C.H.; Aggarwal, R.K.; Song, K.B. Out-of-step detection algorithm using frequency deviation of voltage. IET Gener. Transm. Distrib. 2007, 1, 119-126. [CrossRef]

25. Salimian, M.R.; Aghamohammadi, M.R. Intelligent Out of Step Predictor for Inter Area Oscillations Using Speed-Acceleration Criterion as a Time Matching for Controlled Islanding. IEEE Trans. Smart Grid 2016, $P P$, 1. [CrossRef]

26. Frimpong, E.A.; Asumandu, J.; Okyere, P.Y. Neural Network and Speed Deviation Based Generator Out-Of-Step Prediction Scheme. J. Electr. Eng. 2015, 15, 1-8.

27. Tziouvaras, D.A.; Hou, D. Out-of-step Protection Fundamentals and Advancements. In Proceedings of the 57th Annual Conference for Protective Relay Engineers, College Station, TX, USA, 30 March-1 April 2004; pp. 282-307.

28. Gajić, Z.; Ivanković, I.; Filipović-Grčić, B.; Rubeša, R. New General Method for Differential Protection of Phase Shifting Transformers. In Proceedings of the International Conference on Advanced Power System Automation and Protection (APAP2007), Jeju, Korea, 24-27 April 2007.

29. Glavić, M.; Novosel, D.; Heredia, E.; Kosterev, D.; Salazar, A.; Habibi-Ashrafi, F.; Donnelly, M. Real-Time Voltage Control Under Stressed Conditions, See It Fast to Keep Calm. IEEE Power Energy Mag. 2012, 10, 43-53. [CrossRef]

30. Eissa, M.M.; Masoud, M.E.; Elanwar, M.M.M. A Novel Back up Wide Area Protection Technique for Power Transmission Networks Using Phasor Measurement Unit. IEEE Trans. Power Deliv. 2010, 25, 270-278. [CrossRef]

31. Soman, S.A.; Nguyen, T.B.; Pai, M.A.; Vaidyanathan, R. Analysis of angle stability problems: A transmission protection systems perspective. IEEE Trans. Power Deliv. 2004, 19, 1024-1033. [CrossRef]

32. Grillo, S.; Massucco, S.; Pitto, A.; Silvestro, F. Indices for fast contingency ranking in large electric power systems. IEEE Trans. Power Syst. 2010, 1, 660-666.

33. Blumschein, J.; Yelgin, Y.; Kereit, M. Proper detection and treatment of power swing to reduce the risk of Blackouts. In Proceedings of the Third International Conference on Electric Utility Deregulation and Restructuring and Power Technologies (DRPT 2008), Nanjing, China, 6-9 April 2008.

34. ENTSO-E, European Network of Transmission System Operators for Electricity, "Continental Europe Operation Handbook: Policy 4, Co-Ordinated Operational Planning, Subsections C: Congestion Forecast". Available online: https:/ / www.entsoe.eu/publications/system-operations-reports/operation-handbook/ Pages/default.aspx (accessed on 21 December 2016).

35. Ivanković, I.; Kuzle, I. Transmission System Phase Angle Footprint Based on Synchrophasor Measurements. In Proceedings of the 2016 18th Mediterranean Electrotechnical Conference IEEE MELECON, Limassol, Cyprus, 18-20 April 2016; pp. 1-6.

36. IEEE PSRC WG D6. In Power Swing and Out-of-Step Considerations on Transmission Lines; Report to the Power System Relaying Committee of the IEEE Power Engineering Society; IEEE: Piscataway, NJ, USA, 2005; pp. 1-59.

37. Virmani, S.; Vicković, D.; Savulescu, S.C. Real-Time Calculation of Power System Loadability Limits. In Proceedings of the 2007 IEEE Lausanne Power Tech PES, Power Tech, Lausanne, Switzerland, 1-5 July 2007; pp. 1-6.

38. Yan, J.; Liu, C.C.; Vaidya, U. PMU-Based Monitoring of Rotor Angle Dynamics. IEEE Trans. Power Syst. 2011, 26, 2125-2133. [CrossRef]

39. Huseinbasic, E.; Kuzle, I.; Tomisa, T. Inter-Area Oscillations Damping Using Dynamic Breaking and Phasor Measurements. In Proceedings of the Power Systems Conference \& Exposition (PSCE 2009), Seattle, WA, USA, 15-19 March 2009; pp. 1-6.

40. Franco, R.; Sena, C.; Taranto, G.N.; Giusto, A. Using synchrophasors for controlled islanding-A prospective application for the Uruguayan power system. IEEE Trans. Power Syst. 2013, 28, 2016-2024. [CrossRef]

41. Rubeša, R. HOPS Wide Area Monitoring System recordings of Oscillations on the 14th November 2014; Report for ENTSO-E System Protection and Dynamics Group; Croatian Transmission System Operator Ltd.: Zagreb, Croatia, 2015; pp. 1-12. 
42. Sattinger, W. CE South-East Local Mode Oscillation on Nov 14th 2014; Swissgrid: Laufenburg, Switzerland, 2014.

43. Union of the Co-ordiantion of Transmission of Electricity-UCTE. Final Report-System Disturbance on 4 November 2006; UCTE: Brussels, Belgium, 2007; pp. 1-85.

44. Lukić, M.; Kuzle, I.; Tešnjak, S. An Adaptive Approach to setting Underfrequency Load Shedding Relays for an Isolated Power System with Private Generation. In Proceedings of the IEEE Mediterranean Electrotechnical Conference (MELECON '98), Tel Aviv, Israel, 18-20 May 1998; pp. 1122-1125. article distributed under the terms and conditions of the Creative Commons Attribution (CC BY) license (http:/ / creativecommons.org/licenses/by/4.0/). 